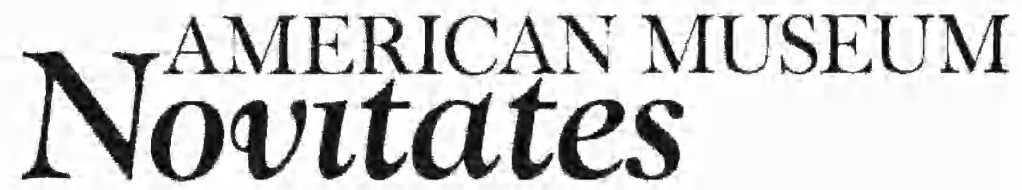

PUBLISHED BY THE AMERICAN MUSEUM OF NATURAL HISTORY CENTRAL PARK WEST AT 79TH STREET, NEW YORK, NY 10024 Number 3599,35 pp., 14 figures, 2 tables

December 12, 2007

\title{
Chubutemys, a New Eucryptodiran Turtle from the Early Cretaceous of Argentina, and the Relationships of the Meiolaniidae
}

\author{
EUGENE S. GAFFNEY, ${ }^{1}$ THOMAS H. RICH ${ }^{2}$ PATRICIA VICKERS-RICH, ${ }^{3}$ \\ ANDREW CONSTANTINE, ${ }^{4}$ RAUL VACCA,${ }^{5}$ AND LESLEY KOOL ${ }^{6}$
}

\begin{abstract}
Chubutemys copellot is the oldest nonmarine cryptodire from South America represented by a skull. The skull and associated postcranial fragments are from the Aptian Cerro Costaño Member of the Cerro Barcino Formation of Chubut, Argentina. Chubutemys has a processus trochlearis oticum, showing that it is a cryptodire, and an enclosed canalis caroticus internus extending to the posterior margin of the pterygoid, showing that it is a eucryptodire. The skull of Chubutemys is similar to that of other primitive eucryptodires, particularly Dracochelys, but also to Hangaiemys, Judithemys, Sinemys, and Ordosemys. Chubutemys differs from all these, however, in possessing a solidly roofed skull, formed by long, wide parietals, rather than a posterior emargination. Chubutemys also differs from these taxa in having no cheek emargination.

A phylogenetic analysis using PAUP* analyzed 104 parsimony-informative characters resolving into one most parsimonious cladogram of 224 steps, a consistency index of 0.55 , and a retention index of 0.74 . The phylogenetic analysis weakly joins Chubutemys and meiolaniids on the basis of the prefrontal-postorbital contact. Chubutemys also has a fully roofed skull and slitlike posterior opening of the foramen caroticum laterale (foramen posterius canalis caroticus laterale), features to be expected in a meiolaniid sister taxon. Chubutemys provides further evidence that meiolaniids

${ }^{1}$ Division of Paleontology, American Museum of Natural History (esg@amnh.org).

${ }^{2}$ School of Geosciences, Monash University, Clayton, Victoria 3800, Australia (Pat.Rich@scimonash.edu.au).

${ }^{3}$ School of Geosciences, Monash University, Clayton, Victoria 3800, Australia; Museum Victoria (trich@museum.vic.

${ }^{4}$ Origin Energy, Brisbane Origin Energy, GPO Box 1461, Brisbane, Queensland 4001, Australia (andrew. constantine@upstream.originenergy.com.au).

${ }^{5}$ Museo Paleontologico Egidio Feruglio, Fontana y Lewis Jones, 9100 Trelew, Chubut Province, Argentina (ramar@infovia.com.ar).

${ }^{6}$ School of Geosciences, Monash University, Clayton, Victoria 3800, Australia (koolasuchas@bigpond.com).
\end{abstract} gov.au). 
are related to "basal" eucryptodires ("sinemydids/macrobaenids"), that is, eucryptodires outside the living Cryptodira, the Polycryptodira,

The basicranial morphology of meiolaniids, with an intrapterygoid slit, rather than being a unique feature of the group is instead a modified state of the primitive eucryptodire condition, as seen in such forms as Chubutemys, Dracochelys, Ordosemys, and Sinemys. The intrapterygoid slit of meiolaniids is homologous with the pterygoid flange associated with the foramen caroticum laterale (foramen posterius canalis caroticus laterale of Sukhanov) in non-Polycryptodiran eucryptodires like Ordosemys.

Chubutemys shows that nonmarine eucryptodires were present in South America in the Cretaceous, as they were in North America, central Asia, and Australia.

\section{INTRODUCTION}

The record of nonmarine cryptodires in South America is very sparse, particularly in comparison to the more abundant pleurodires. There is a record of marine cryptodires from the Jurassic, but the nonmarine record has been restricted to the eucryptodiran Meiolaniidae from the late CretaceousPaleogene. Recent vertebrate paleontological field explorations (Rich et al., 1998) in the Early Cretaceous of the Province of Chubut, Argentina, have yielded the oldest skull of a South American cryptodire and the oldest record of a nonmarine cryptodire from South America. The only older cryptodire is the late Jurassic (Tithonian) Neusticemys neuquina (Fernandez and Fuente, 1993), a presumably marine form attributed to the "Plesiochelyidae-Thalassemydidae" by Gasparini and Fernandez (1997) and the "?Plesiochelyidae" by Fernandez and Fuente (1993). Neusticemys neuquina occurs with the pleurodire Notoemys, The skull and cervical vertebrae of Neusticemys neuquina are unknown and thus its more precise relationships are indeterminate at present. Broin (1993) listed some Jurassic localities that have yielded turtles, none identified as nonmarine cryptodires. Broin and Fuente (1993b: 182) also listed "chelidae primitifs" from the Rio Limay Formation, thought to be CenomanianTuronian, but the basis of the identification is unknown and these must be considered Testudines indet. until described.

The Albian Santana Formation (Maisey, $1990,1991)$ has yielded a protostegid marine cryptodire (Hirayama, 1998) that is probably later in time than the Chubut cryptodire. The University of California has a skull and partial skeleton (UCMP 38346) of an undescribed chelonioid from the vicinity of Bogota, Colombia (V 4538), that may be Aptian-
Barremian in age (Welles, 1962) and thus as old as or older than the Chubut cryptodire. However, this material has never been described and its age is not substantiated.

Later records of cryptodires in South America that postdate the Aptian Chubut cryptodire consist of meiolaniids:

1. Los Alamitos Fm., Rio Negro Province, Argentina, Campanian-Maastrichtian, described by Broin (1987).

2. Salinas de Trapalco, Rio Negro Province, Argentina, Campanian-Maastrichtian, undescribed fragments reported by Broin and Fuente (1993a,b).

3. Sarmiento Fm., Chubut Province, Argentina, Eocene, tail ring described by Fuente and Fernandez (1992).

4. Niolamia argentina, Cretaceous or Eocene, Chubut Province, complete skull, see Gaffney (1996) for most recent appraisal.

Another record, identified as a pleurodire: "grand Chelidae primitif" by Broin and Fuente (1993b, see Discussion below), is probably a cryptodire similar to Chubutemys described here.

Although cladistic analysis has been the norm for phylogenetic work (at least in morphology) for decades, recently some have argued that there are limitations in the Linnaean classification system that require its complete abandonment in favor of an alternative, the PhyloCode, incorrectly called by some, "Phylogenetic Taxonomy" (De Queiroz and Gauthier, 1992). Although we do see some problems with the Linnaean system as an exact mirror of a cladogram, with taxon names that can change in content with every addition or subtraction of a basic taxon or character, we do not think that abandonment and creation of a new system is 
the answer. We take a more traditional view, similar to that expressed by Gaffney et al. (2006; see also Nixon and Carpenter, 2000; Carpenter, 2003; Nixon et al., 2003; Schuh, 2003), that it is better to modify the Linnaean system where convenient, rather than set up a new one, particularly a rankless one. An extreme example of the abandonment of the more traditional system of turtle classification is the Joyce et al. (2004) version of the PhyloCode (q.v.) in which most of the previously named higher taxa of turtles, including the name Cryptodira, have been replaced or redefined with new content. Although this exercise claimed to improve stability in turtle nomenclature, it is obvious that the opposite is the case. In fact, the two proponents of new higher category definitions and names for turtles (Lee, 1995; Joyce et al. 2004) do not themselves agree on the taxon names or definitions. Another classification aspect is the use of geological range in naming groups, the "stem" and "crown" nomenclature, referring to whether taxa include living species. We think that since extinction is not an element of the cladogram, it should not be an element of the classification, which is cumbersome enough without the added burden of geological range. Therefore, we use the higher taxon names for cryptodires explicated in Gaffney (1996) for the taxa that are relevant in this discussion of Chubutemys.

The anatomical terminology used here is developed in Gaffney $(1972,1979)$. The term "foramen caroticum laterale" as currently used actually refers to both a more anterior foramen opening into the braincase floor and a more posterior foramen opening on the roof of the palate, with the canalis caroticus lateralis (Gaffney, 1979 and others) connecting them. Sukhanov (2000) used the term "foramen posterius canalis caroticus laterale" for the posterior foramen, and we have adopted that usage here.

The Chubut cryptodire is most similar to a series of largely Mesozoic eucryptodires usually grouped as the family Sinemydidae (Gaffney, 1996; Sukhanov, 2000), but which may also be interpreted as successive, paraphyletic, sister taxa to the Polycryptodira of Gaffney (1984, 1996). As has been done in previous literature (Brinkman and Peng, 1993a, 1993b; Brinkman and Wu, 1999; Gaffney, 1996; Gaffney and Ye, 1992; Parham and Hutchison, 2003; and Sukhanov, 2000 ), we refer to these early eucryptodires as "Sinemydidae/Macrobaenidae" for convenience and to indicate the inconsistent nature of phylogenetic analyses of these taxa. Earlier works that have reviewed some of these taxa are Brinkman and Peng (1993a, 1993b), Brinkman and Wu (1999), Gaffney and Ye (1992), Gaffney (1996), Parham and Hutchison (2003), and Sukhanov (2000). Specific taxa that have skulls and/or postcrania particularly relevant to the description of the Chubut cryptodire and that are referred to in this text are:

1. Dracochelys: Gaffney and Ye (1992), Brinkman (2001).

2. Ordosemys: Brinkman and Peng (1993a), Brinkman and Wu (1999).

3. Xinjiangchelys: Peng and Brinkman (1993b), Kaznyshkinet al. (1990).

4. Hangaiemys: Sukhanov and Narmandakh (1974), Sukhanov (2000), Parham and Hutchison (2003).

5. Sinemys: Brinkman and Peng (1993b).

6. Meiolaniidae (including Meiolania, Ninjemys, Warkalania, and Niolamia): Gaffney (1983, 1996).

7. Otwayemys: Gaffney et al. (1998). See Smith (1999) for another possible Australian eucryptodire from the early Cretaceous.

8. Judithemys: Gaffney (1996, as TMP 87.2.1), Parham and Hutchison (2003). Skull figured in fig. 13.

9. Macrobaena: Tatarinov (1959).

\section{Institutional AbBreviations}

CNEA Comisión Nacional de Energía Atómica

MACN Museo Argentino de Ciencias Naturales

MPEF Museo Paleontológico Egidio Feruglio

TMP Tyrell Museum of Paleontology

UCMP University of California at Berkeley

Anatomical Abbreviations

bo basioccipital

bs basisphenoid 


$\begin{array}{ll}\text { cci } & \text { canalis caroticus internus } \\ \text { ex } & \text { exoccipital } \\ \text { fcb } & \text { foramen caroticum basisphenoidale } \\ \text { fpcci } & \begin{array}{l}\text { foramen posterius canalis carotici } \\ \text { interni } \\ \text { fpcl }\end{array} \\ \text { foramen posterius canalis caroticus } \\ \text { fpp } & \text { fenestra palatinum posterius } \\ \text { fr } & \text { frontal } \\ \text { ju } & \text { jugal } \\ \text { mx } & \text { maxilla } \\ \text { op } & \text { opisthotic } \\ \text { pa } & \text { parietal } \\ \text { pal } & \text { palatine } \\ \text { pf } & \text { prefrontal } \\ \text { po } & \text { postorbital } \\ \text { pt } & \text { pterygoid } \\ \text { qj } & \text { quadratojugal } \\ \text { qu } & \text { quadrate } \\ \text { so } & \text { supraoccipital } \\ \text { sq } & \text { squamosal } \\ \text { vo } & \text { vomer } \\ \end{array}$

\section{SYSTEMATICS}

ORDER TESTUDINES LINNAEUS, 1758

\section{INFRAORDER CRYPTODIRA COPE, 1864}

\section{PARVORDER EUCRYPTODIRA GAFFNEY, 1975}

\section{FAMILY INDETERMINATE} ("SINEMYDIDAE/MACROBAENIDAE")

Chubutenys, new genus

TrPe SPEcies: Chubutemys copelloi, new genus and species.

Distribution: Aptian, Early Cretaceous, Cerro Costaño Member, Cerro Barcino Formation.

ETYMOLOGy: Chubut, for province of Argentina in which it was found,

Diagnosis: A genus of eucryptodire known only from the skull, similar to Dracochelys, Hangaiemys, and Ordosemys, nasal-frontal contact absent in contrast to Ordosemys; frontal does not enter orbit in contrast to Dracochelys, Ordosemys, Hangaiemys, and Sinemys; temporal roof broadly covered by parietals extending posterior to otic chamber in contrast to the deep emargination seen in Hangaiemys, Judithemys, Ordosemys, and Sinemys (and probably
Dracochelys, although the temporal roof is incompletely known); broad parietal-squamosal contact in contrast to Dracochelys, Ordosemys, Hangaiemys, and Sinemys; cheek emargination absent in contrast to Dracochelys, Hangaiemys, Judithemys, Ordosemys, and Sinemys; triturating surface narrow as in Ordosemys and Sinemys, but not very narrow as in Dracochelys and Hangaiemys; foramen palatinum posterius similar in size to that in Ordosemys, not very large as in Dracochelys and Hangaiemys; deep pit on pterygoid absent in contrast to Dracochelys and Ordosemys; foramen posterius canalis caroticus laterale exposed in ventral view, widely separated from foramen caroticum basisphenoidale, and formed in gap between pterygoid and basisphenoid as in Dracochelys and Niolamia, in contrast to more posterior position as in Hangaiemys, Judithemys, Sinemys, and Ordosemys; canalis caroticus internus only partially floored by bone along contact of basisphenoid and pterygoid as in Dracochelys, Hangaiemys, Ordosemys, and Sinemys; foramen caroticum basisphenoidale formed entirely by basisphenoid and open ventrally as in Dracochelys, Ordosemys, Hangaiemys, and Sinemys; basisphenoid triangular in ventral view as in Dracochelys and Niolamia, not rectangular as in Ordosemys and Hangaiemys.

\section{Chubutemys copelloi, new species}

TYPE SPECIMEN: MPEF-PV1236, a partial skull lacking much of the bone from its dorsal surface, but with an internal mold of it present, ventral surfaces preserved intact with stapes in situ, atlas elements disarticulated, and a piece of presumed hyoid in right temporal fossâ.

Type Locality: "Turtle Town", 43 $36^{\prime} \mathrm{S}$, $68^{\circ} 55^{\prime} \mathrm{W}$ (figs. 1-3; Rich et al., 1998: fig. 1), Chubut Province, Argentina.

Horizon: Cerro Castaño Member (fig. 3), Cerro Bareino Formation, Chubut Group, Aptian (Codignotto et al., 1978; Rich et al., 1998; Rauhut et al., 2003) based on the work of two of the authors, T. Rich and A. Constantine.

Diagnosis: as for genus.

Etymology: For Maria Copello, who discovered the holotype. 


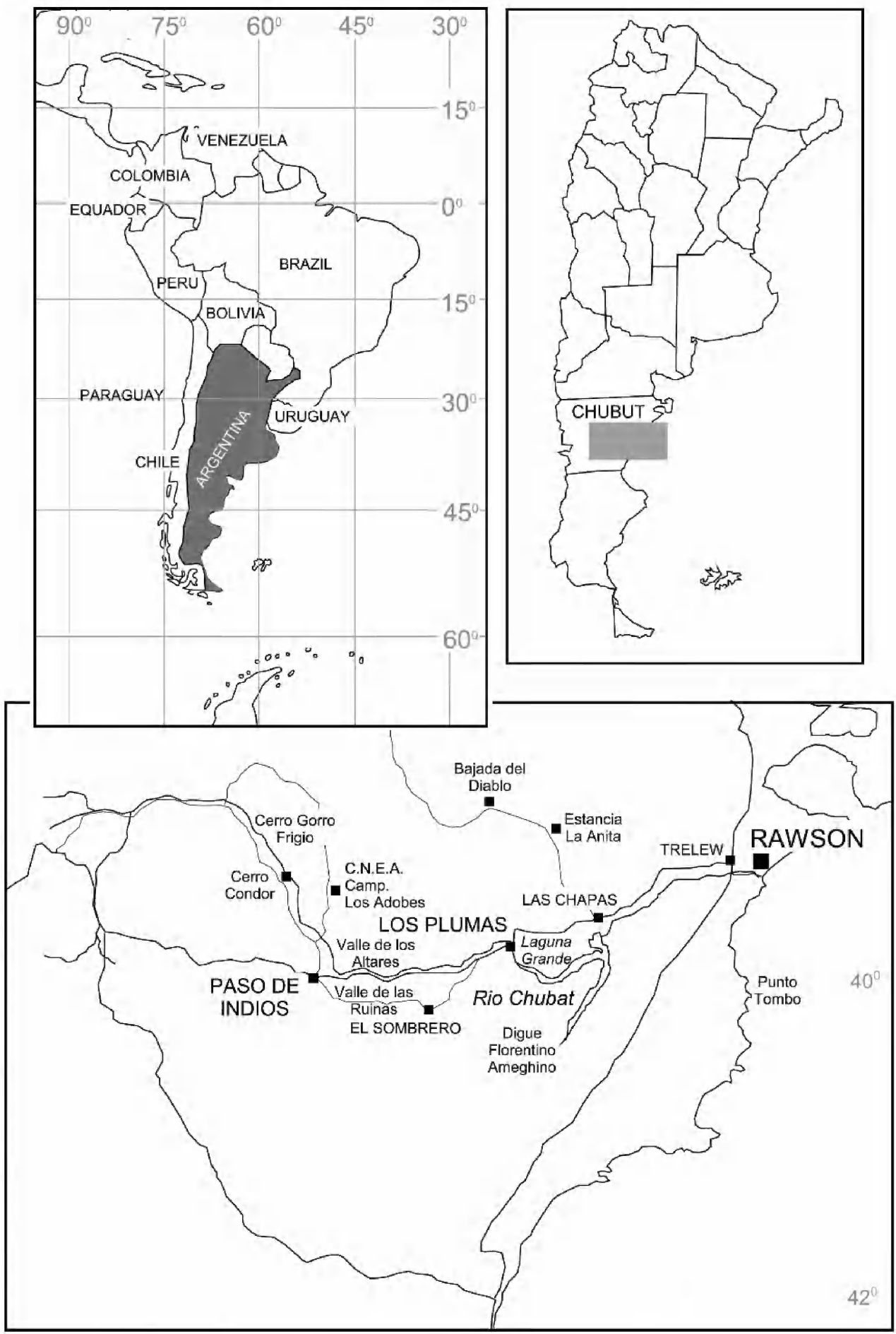

Fig. 1. Regional location maps showing the position of the type locality of Chubutemys copelloi, n. gen. et sp. MPEF-PV1236 (from Rich et al., 1998). 


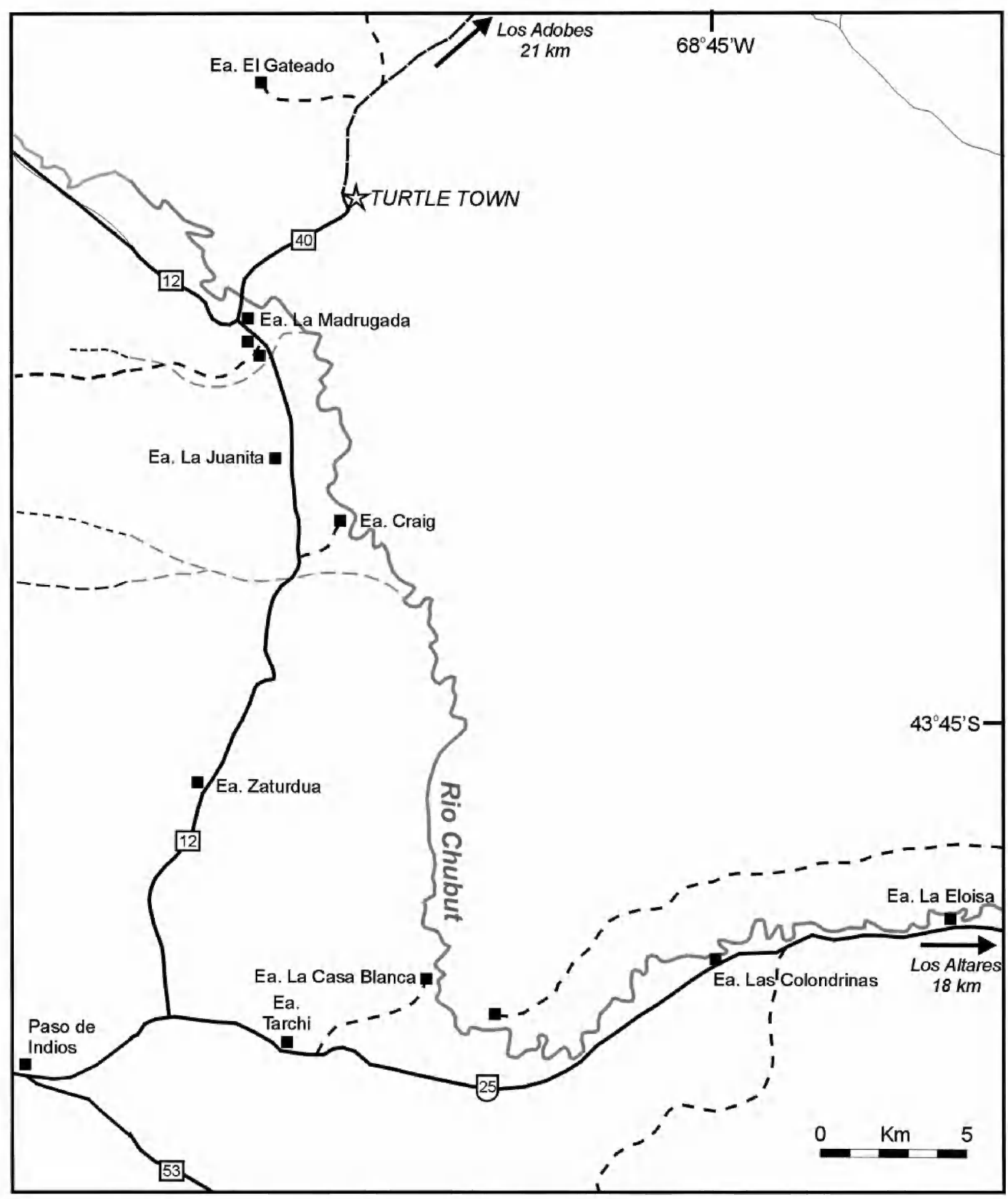

Fig. 2. Detailed location map (from $250 \mathrm{~K}$ topographic map) showing the position of the type locality of Chubutemys copelloi, n. gen. et sp. MPEF-PV1236.

Referred Material: The locality that yielded the skull of Chubutemys also coughed up enough turtle remains to cause its giddy discoverers to call it "Turtle Town" (figs. 1-3; Rich et al., 1998: fig. 1). The fossils from the site consist of shell and postcranial fragments of cryptodires and pleurodires, as well as the skull described here. No shell or postcranial material was found directly associated with the type skull of Chubutemys. However, there are postcranial elements that probably belong to Chubutemys. The cryptodire material is identifiable because it consists of a partial carapace with anterior thoracic centra and an 
articulated eighth cervical, as well as peripherals, including bridge peripherals, that are very similar to the "sinemydid/macrobaenid" postcrania described for Dracochelys, Ordosemys, Hangaiemys, Judithemys, and Otwayemys. The shell fragment with an eighth cervical, MPEF PV1940, is identified as a cryptodire on the basis of the widely spaced zygapophyses and the close agreement of this cervical with those of Ordosemys and Dracochelys (see below). Three sets of peripherals are also identified as cryptodire and probably belong to Chubutemys. These are MPEF PV1941, PV1942, and PV1943. They are very similar to peripherals figured by Brinkman (2001) for Dracochelys. They are relatively flat, show extensive costo-peripheral fontanelles, and have dorsally concave guttering as in Dracochelys.

There is at least one other species of turtle at this locality, a chelid pleurodire much smaller than Chubutemys. Most of these chelid bones differ from the cryptodire in being at least half the size and in having a very differently shaped shell with fused pelvis, no costo-peripheral fontanelles, and finely incised sulci.

Discussion: Discovery of a definitive, skull-based eucryptodire in the Early Cretaceous of Argentina prompts reexamination of the published record, which has generally referred nonmarine turtles to the Pleurodira or Meiolaniidae (Broin and Fuente, 1993). Much of this material is too fragmentary to reassess with confidence, but two specimens previously identified as pleurodires are probably cryptodires. These were originally identified as "grand Chelidae primitif indetérminé" (Broin and Fuente, 1993b: fig. 5, 18-19) from the Los Alamitos, Rio Negro, Late Cretaceous. Both specimens are in the Museo Argentino de Ciencias Naturales and have been examined by the senior author (E.S.G.). MACN 907 was identified as a fifth cervical, but it is very similar to the undoubted eighth cervical of MPEF PV1940. Both are biconvex with a narrowed centrum and a wide, midway positioned transverse process, distinct from any described chelid. MACN 907 lacks the neural arch as well as the zygapophyses. The principal difference between them is that the anterior central articulation of MPEF PV1940 is slightly larger than the posterior one, whereas in MACN 907 they are closer in size. The other specimen, MACN 908, identified as an eighth cervical (Broin and Fuente, 1993), probably is an eighth; it agrees closely with MACN 907 but lacks transverse processes and a neural arch and only shows a biconvex centrum, so its identity must remain ambiguous. Nonetheless, it is very likely that MACN 908 is also a eucryptodire, along with MACN 907.

\section{GEOLOGY}

Location: The "Turtle Town" fossil locality (Rich et al., 1998) is situated in the center of Chubut Province approximately $32 \mathrm{~km}$ north of Paso de Indios, on the north side of the Rio Chubut (figs. 1-3). Most of the best turtle remains were found at a site (site A: $43^{\circ} 35^{\prime} 51^{\prime \prime} \mathrm{S}, 68^{\circ} 54^{\prime} 37^{\prime \prime} \mathrm{W}$ ) approximately $150 \mathrm{~m}$ east of the road (Route 40) leading north to the Los Adobes Mine, while a second, less productive site (site B: $43^{\circ} 35^{\prime} 52^{\prime \prime} \mathrm{S}$, $68^{\circ} 54^{\prime} 45^{\prime \prime} \mathrm{W}$ ) approximately $400 \mathrm{~m}$ to the west of the site A, but on the opposite side of the road, has also yielded a few turtle fragments in addition to a large sauropod phalanx and a well-preserved seed cone.

Stratigraphy: The Early Cretaceous Chubut Group of Argentina is a sequence of fossiliferous nonmarine epiclastic and pyroclastic sediments up to $1500 \mathrm{~m}$ thick (Figari and Courtade, 1993) that crop out over a large part of central Patagonia. The sediments unconformably overlie Middle-Late Jurassic volcanics and nonmarine sediments of the Cañadón Asfalto and Marafil Formations, and are unconformably overlain by latest Cretaceous (Campanian-Maastrichtian) continental to marginal marine to marine sediments of the La Colonia, Paso de Sapo, and Lefipan Formations (Figari and Courtade, 1993). The Chubut Group is presently divided into two formations called the Los Adobes Formation and Cerro Barcino Formation, based on sediment composition and depositional process. The older Los Adobes Formation is dominated by epiclastic sediments derived from the underlying Jurassic volcanic basement (unpublished CNEA report: Cerro Solo 1998, Un Proyecto Para La Produccion de Uranio y Molibdeno en la Patagonia. CAE-UAG 

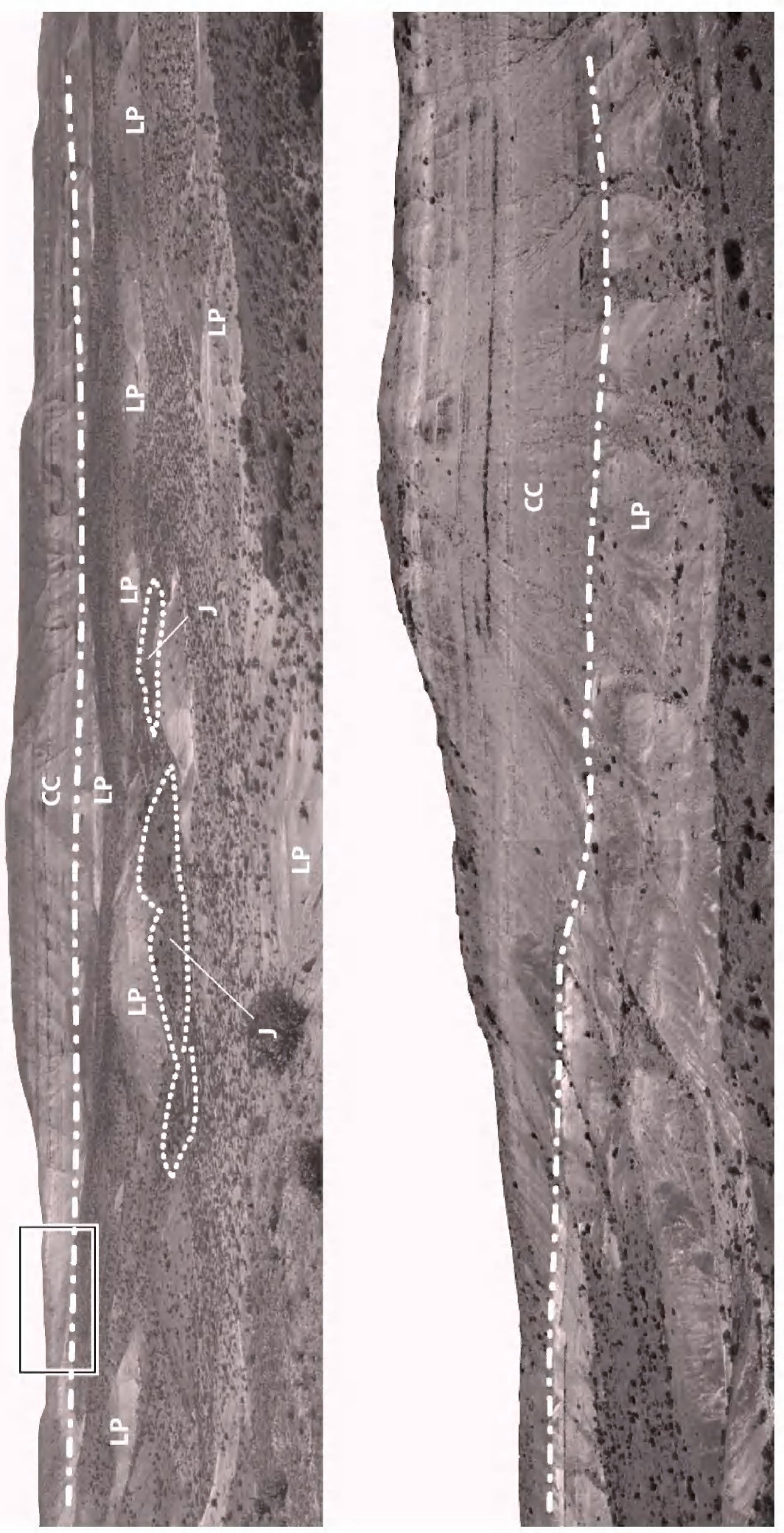
Geologia Economica y Regional Patagonia). It is thought to be Late Valanginian-Hauterivian in age (Cortiñas, 1996; Page et al., 1999) and is subdivided into two units called the Arroyo del Pajarito Member and Bardas Coloradas Member. The lower unit, the Arroyo del Pajarito Member, is represented by up to $150 \mathrm{~m}$ of yellowish-gray to orange-brown, interbedded sandstone, pebbly sandstone, pebble-cobble conglomerate, and minor shale deposited in a high-energy, low-sinuosity fluvial environment. The overlying Bardas Coloradas Member is up to $30 \mathrm{~m}$ thick and is composed largely of red to reddish-brown shale and minor fine-grained sand deposited in a lower energy fluvial overbank environment. Both units are well exposed at the Los Adobes Mine $\left(43^{\circ} 21^{\prime} 43 \mathrm{~S}, 68^{\circ} 45^{\prime} 22^{\prime \prime} \mathrm{W}\right)$ approximately $32 \mathrm{~km}$ north-northeast of "Turtle Town", while another good exposure of the Bardas Coloradas Member can be found on the road leading up to the La Baritina Mine (43 $28^{\prime}$ $\left.35^{\prime \prime} \mathrm{S}, 68^{\circ} 56^{\prime} 09^{\prime \prime} \mathrm{W}\right)$ approximately $15 \mathrm{~km}$ to the north.

The Cerro Barcino Formation, in contrast, contains large volumes of pyroclastic sediments and is thought to be late Hauterivian to Cenomanian in age (Page et al., 1999). It is currently subdivided into five units called (in ascending stratigraphic order) the La Paloma, Cerro Castaño, Las Plumas, Puesto Manuel Arce, and Bayo Overo Members. Only two of these units crop out in the vicinity of "Turtle Town": the La Paloma Member and Cerro Castaño Member.

The La Paloma Member (fig. 3) is a sequence of interbedded pale light gray, pale bright green, and pale reddish-brown (occasionally deep red and purple) tuff, siltstone, claystone, and rare, very fine to fine-grained sandstone and limestone up to $35 \mathrm{~m}$ thick that conformably overlie the Bardas Coloradas Member of the Los Adobes Formation. The basal contact is well exposed at several localities on the northern $\left(43^{\circ} 12^{\prime} 03^{\prime \prime} \mathrm{S}\right.$, $\left.68^{\circ} 52^{\prime} 26^{\prime \prime} \mathrm{W}\right)$ and southwestern $\left(43^{\circ} 13^{\prime} 32^{\prime \prime} \mathrm{S}\right.$, $\left.68^{\circ} 57^{\prime} 24^{\prime \prime} \mathrm{W}\right)$ sides of Cerro Chivos approximately $45 \mathrm{~km}$ north of "Turtle Town".

The Cerro Castaño Member (fig. 3) is a sequence of interbedded reddish-brown, brown, and pale gray (occasionally white, yellowish brown, and pale orange-brown) tuffs, siltstone, and fine to coarse-grained sandstone in excess of $90 \mathrm{~m}$ thick that conformably overlie the La Paloma Member. The difference in color between these two units is quite dramatic when both are present in the same outcrop. The contact is often very sharp, and in some places, a thin lenticular coarse-grained sandstone with intraformational clasts can be found at the base of the Cerro Castaño Member.

All of the vertebrate fossils recovered from "Turtle Town" were found lying on the upper surface of outcrops of the La Paloma Member, In this area, Los Adobes Formation is absent and the La Paloma Member rests unconformably on the Jurassic Lonco Trapial Formation. The basal contact is well exposed in a $1.5-\mathrm{km}$-long section of cliffs up to $30 \mathrm{~m}$ in height on the northeastern side of the Rio Chubut $\left(43^{3} 35^{\prime} 51^{\prime \prime} \mathrm{S}, 68^{\circ} 56^{\prime} 44^{\prime \prime} \mathrm{W}\right)$ approximately $2 \mathrm{~km}$ west of "Turtle Town". Here the La Paloma Member dips very gently $\left(<2^{\circ}\right)$ to the east and infills/blankets the top of the Lonco Trapial Formation, which can vary in relief up to $12 \mathrm{~m}$ over a distance of approximately $100 \mathrm{~m}$ (fig. 3). The basal unconformity is also exposed in the floor of a broad gully about $1.5 \mathrm{~km}$ northwest of "Turtle Town" $\left(43^{\prime} 35^{\prime} 29^{\prime \prime} \mathrm{S}, 68^{\circ} 57^{\prime} 05^{\prime \prime} \mathrm{W}\right)$ where several small mounds of Jurassic basement can be seen protruding up to $4 \mathrm{~m}$ above the surrounding La Paloma Member sediments in the floor of the depression.

The depositional setting of the La Paloma Member at "Turtle Town" is difficult to assess due to the abundance of clay minerals in the sediments, which upon weathering effectively destroy all sedimentary structures. Consequently, the upper surface of the La Paloma Member on gentle to moderate slopes

Fig. 3. Upper, view looking west $\left(43^{\circ} 35^{\prime} 29^{\prime \prime} \mathrm{S}, 68^{\circ} 57^{\prime} 05^{\prime \prime} \mathrm{W}\right)$ at outcrops of Lonco Tropial Formation (J) protruding above La Paloma Member (LP) sediments in floor of gully, Cerro Castaño Member (CC) visible in background; lower, enlarged view of area shown in box in left side of upper view, line is contact between La Paloma Member (LP) and Cerro Castaño Member (CC). 


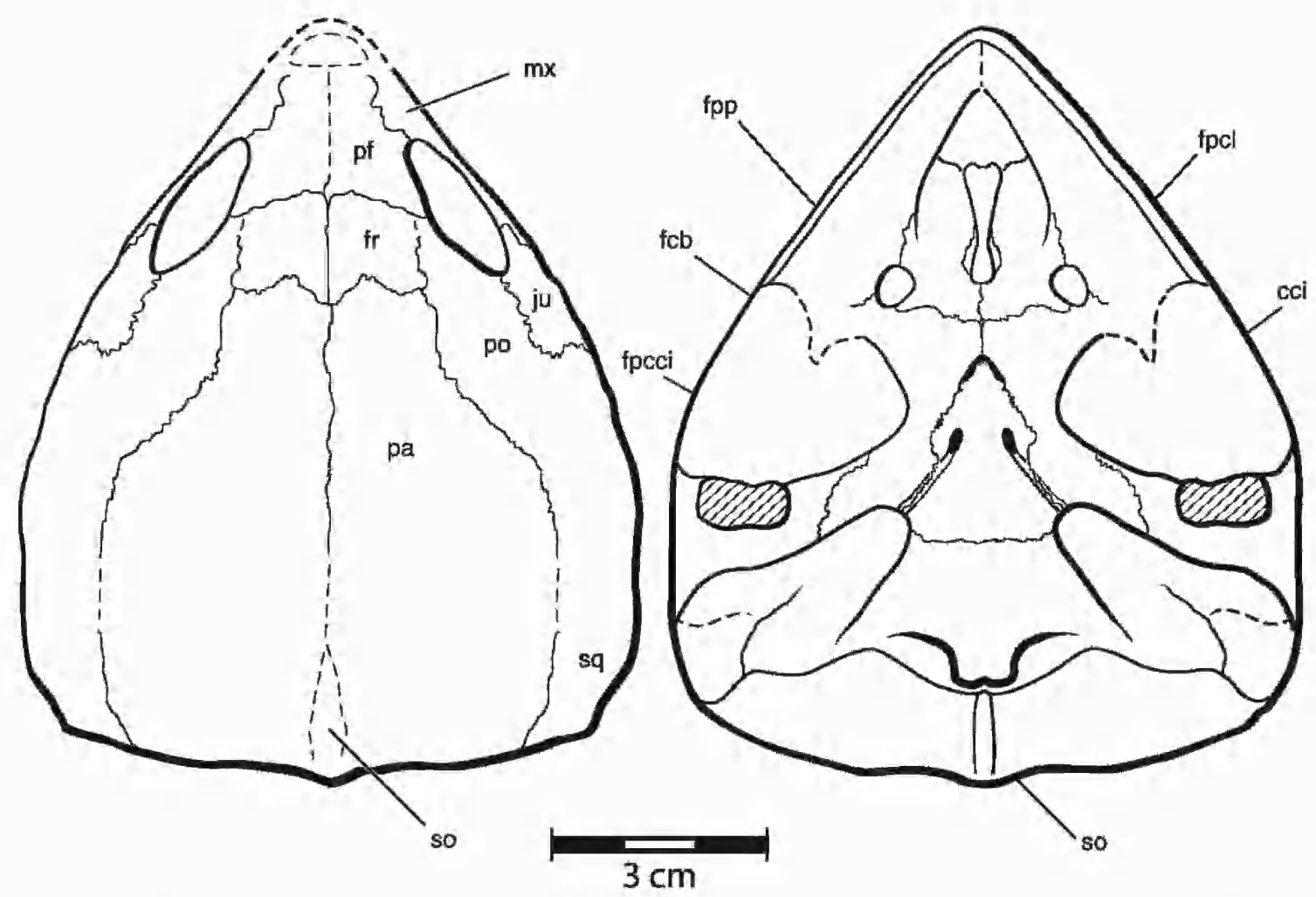

Fig. 4. Chubutemys copelloi, n. gen. et sp. MPEF-PV1236. Restored skull: left, dorsal; right, ventral.

$\left(<30^{\circ}\right)$ often has a "popcorn-like" appearance with a deep weathering profile. This problem is further compounded by sediment being washed down the slopes from higher up, which masks the outcrop lower down and necessitates trenching to reveal the true color and lithology of the underlying sediments.

Mapping in the area of site $\mathrm{A}$ indicates that the vertebrate remains found at this location are from a thin band of silcrete less than $1 \mathrm{~cm}$ thick that contains abundant, randomly oriented, millimeter- to centimeter-sized pieces of silicified plant fragments and stems of branches up to $1 \mathrm{~cm}$ in diameter and occasionally short sections of tree trunks up to $20 \mathrm{~cm}$ in width. The silcrete band crops out along the top of a ridge and forms small pavement surfaces. The silcrete band occurs above a 1.8-m-thick laminated pale gray calcareous siltstone that in turn overlies an 8-m-thick bright green massive tuff. Both facies are weakly bioturbated in places, which suggests the plant matter in the fossiliferous silcrete band probably accumulated on the floor or edge of a lake prior to cementation.

\section{MORPHOLOGIC DESCRIPTION}

Figure 4 is a partially restored view of the skull, figs. 5-9 are stereophotographs of the skull and fig. 10 is a key to the stereophotographs. The reader should also see tables 1 and 2.

\section{NASAL}

The anterior end of the skull is badly eroded; nasals could have been present or absent.

\section{Prefrontal}

The external surface of both prefrontals is badly eroded but enough remains on the right side to see a maxilla contact anterolaterally and a frontal contact posteriorly. As preserved, the 

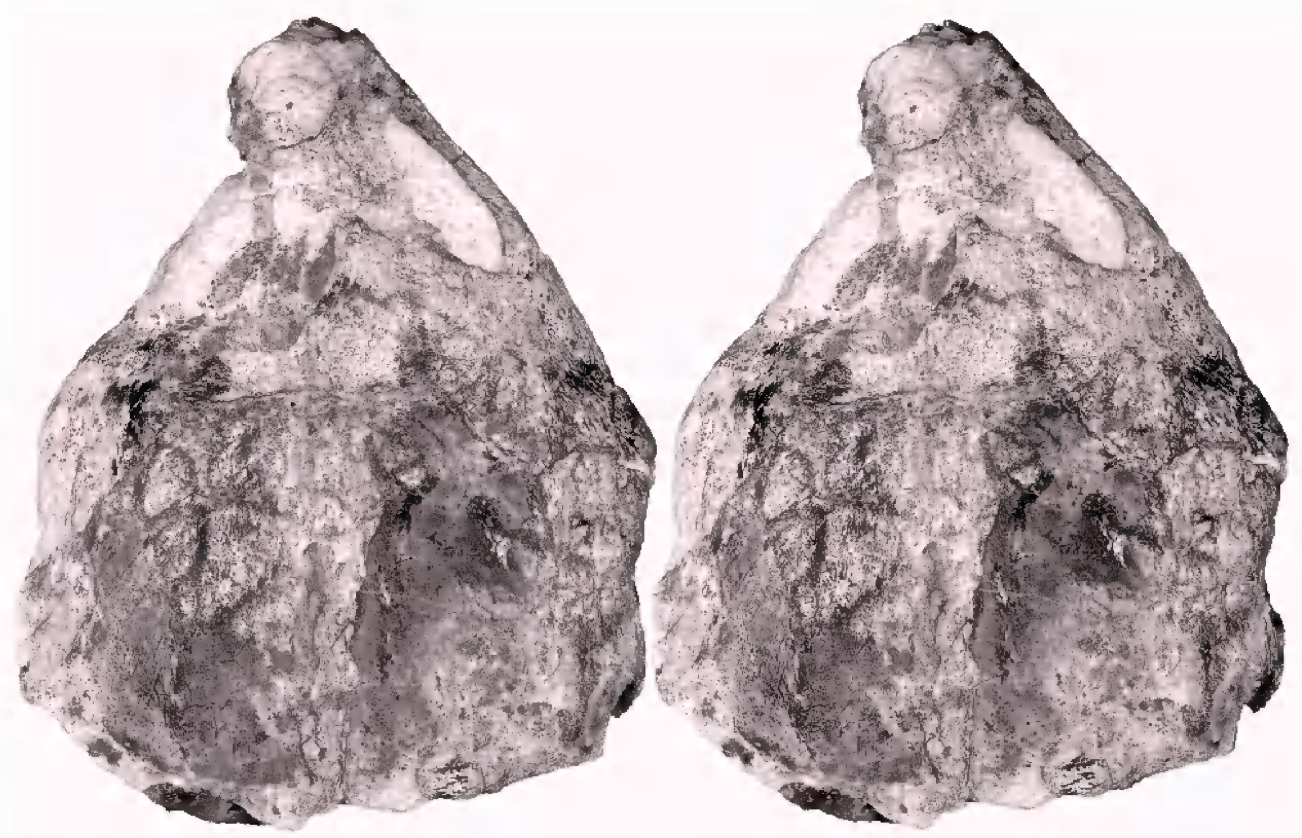

Fig. 5. Chubutemys copelloi, n. gen. et sp. MPEF-PV1236, holotype. Dorsal view of skull.
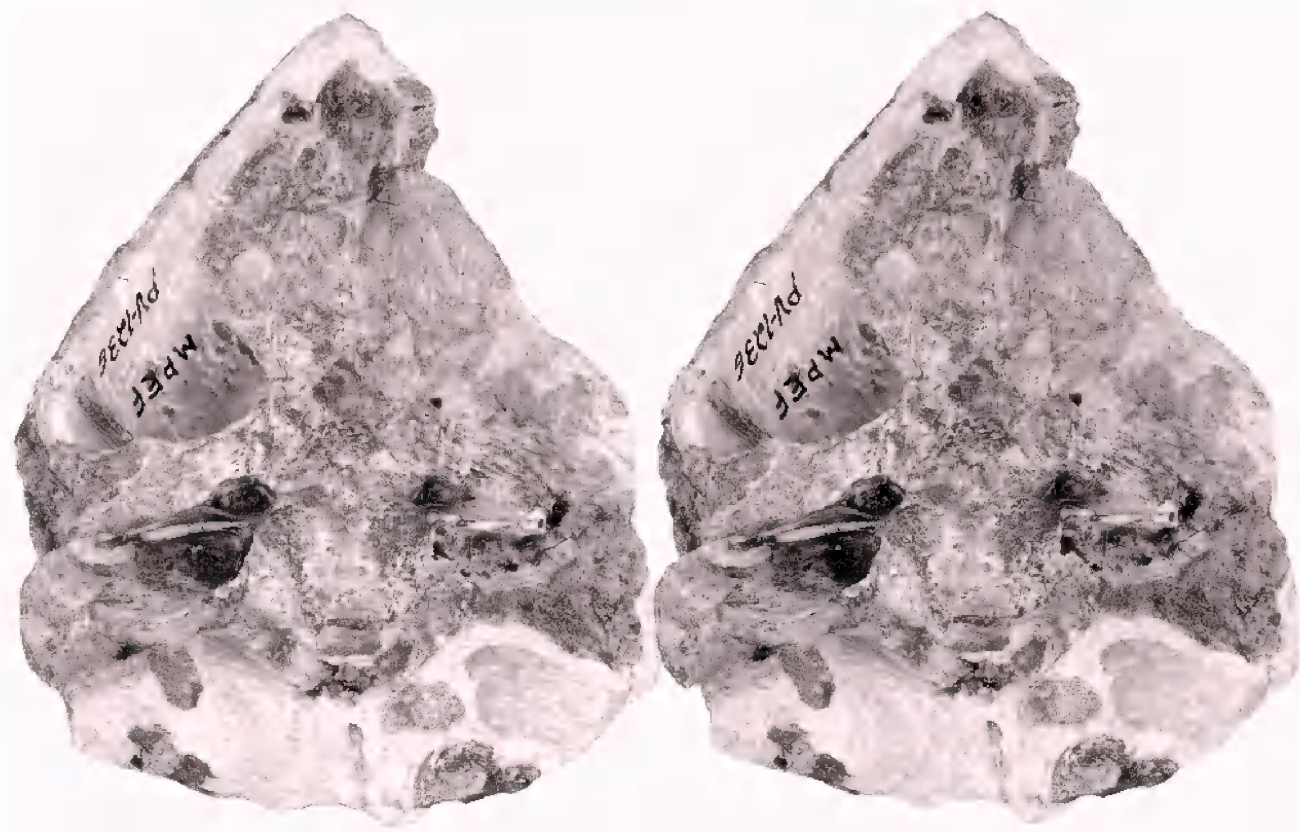

Fig. 6. Chubutemys copelloi, n. gen. et sp. MPEF-PV1236, holotype. Ventral view of skull. 

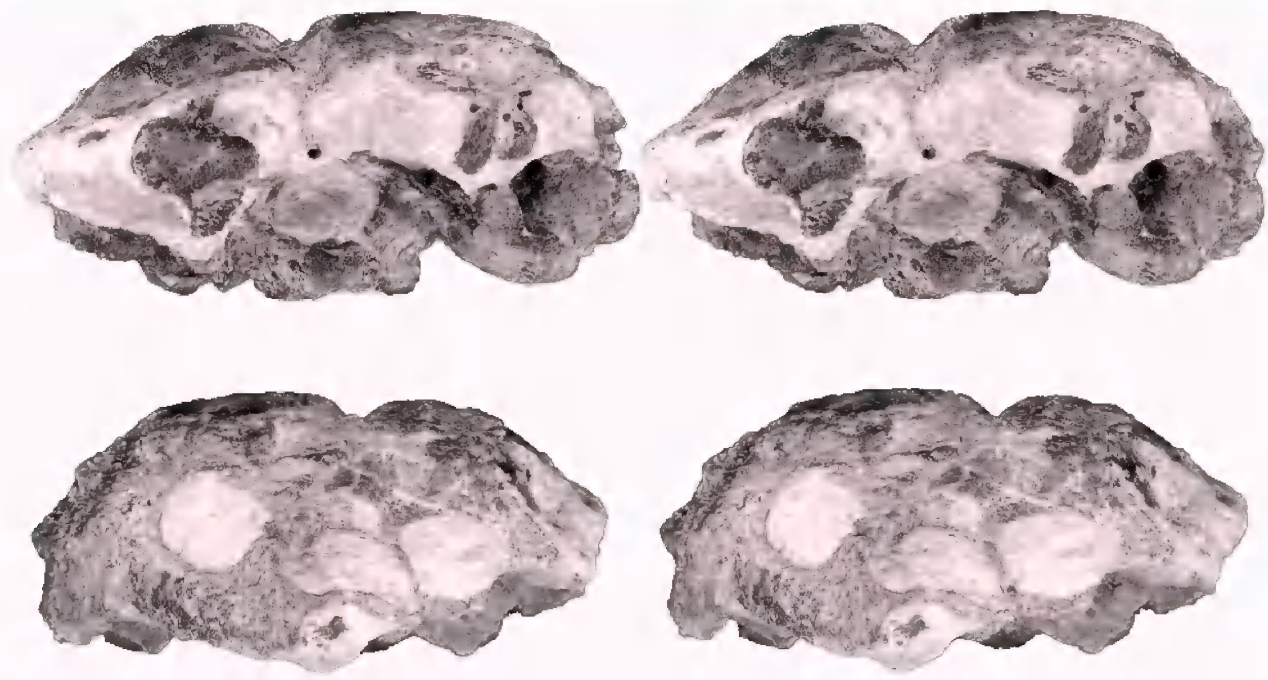

Fig. 7. Chubutemys copelloi, n. gen. et sp. MPEF-PV1236, holotype. Upper, posterior view of skull. Lower, anterior view of skull.
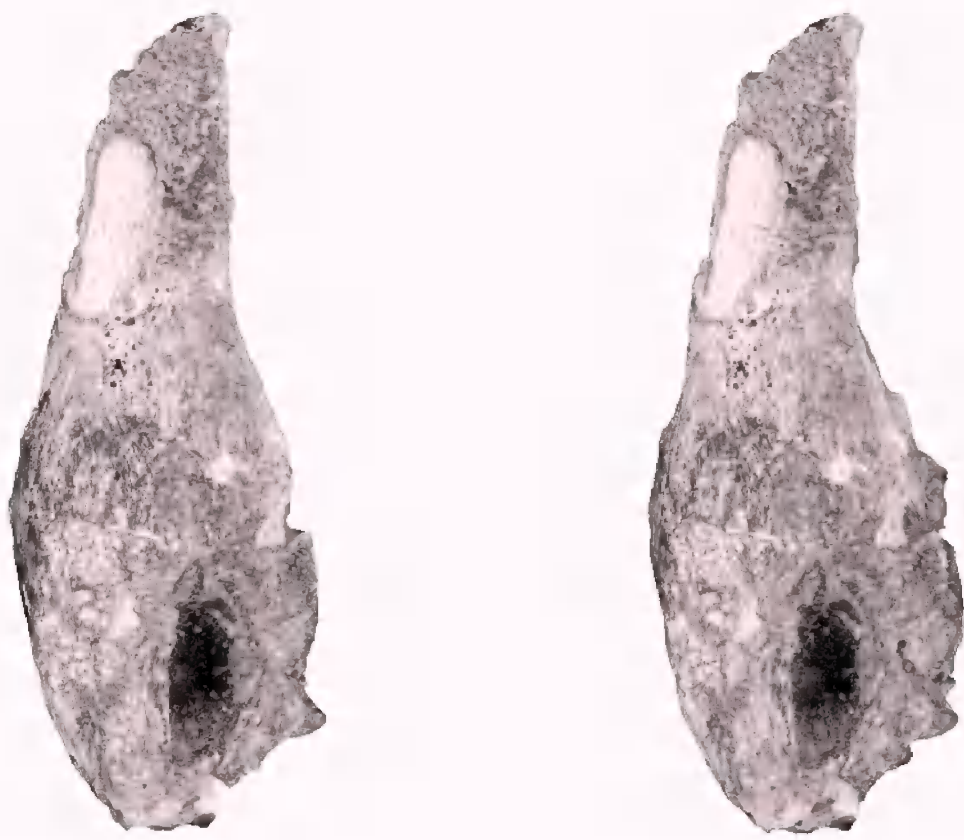

Fig. 8. Chubutemys copelloi, n. gen. et sp. MPEF-PV1236, holotype. Right lateral view of skull. 

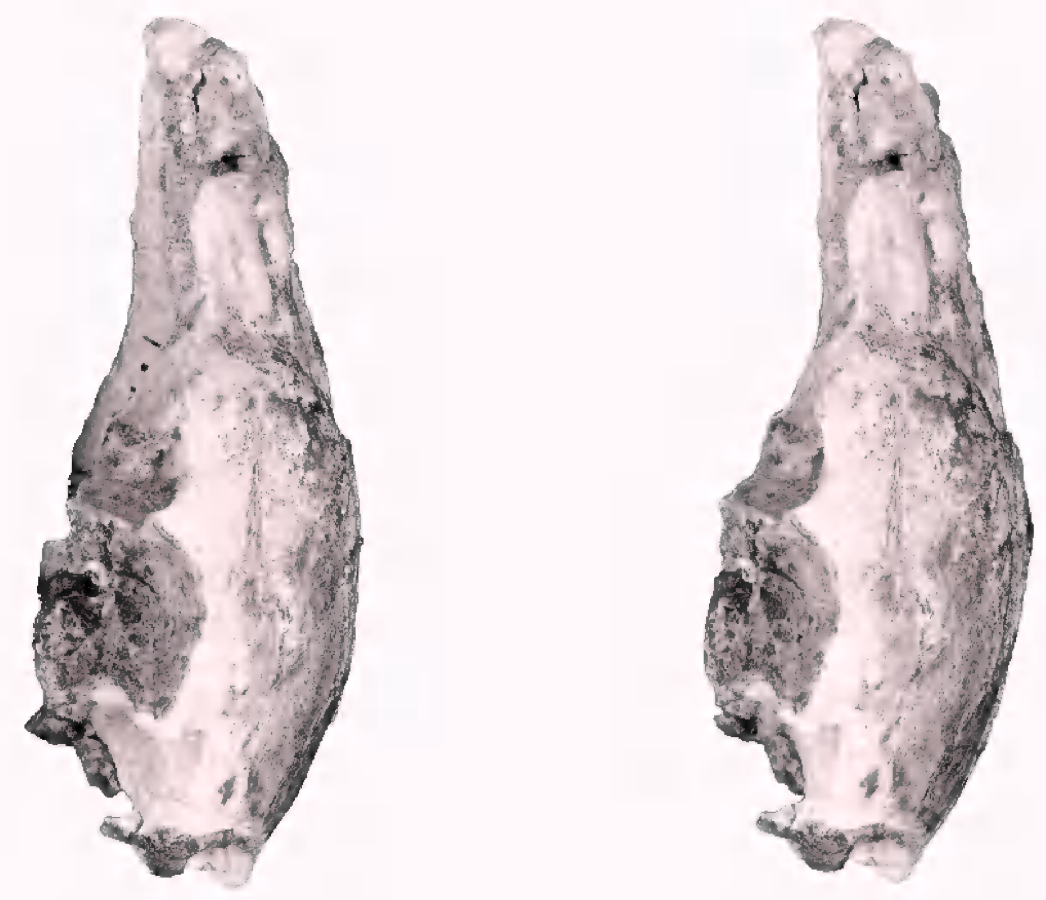

Fig. 9. Chubutemys copelloi, n. gen. et sp. MPEF-PV1236, holotype. Left lateral view of skull.

prefrontal meets the other prefrontal in a long midline suture completely preventing the frontal-nasal contact and anterior frontal contact seen in Ordosemys. The prefrontal of Chubutemys as preserved is consistent with both Dracochelys and Hangaiemys.

\section{FrontAL}

Most of the right frontal is preserved, but the dorsal surfaces are eroded off. The left frontal is largely represented by a mold in matrix of its internal surface. The frontal of Chubutemys is relatively small and does not seem to reach the orbital margin due to a prefrontal-postorbital contact. Such a contact is present in Meiolania and absent in Dracochelys, Ordosemys, and Hangaiemys, although only a relatively narrow projection of frontal reaches the orbit in those forms. However, the poor preservation of the frontal in Chubutemys must be kept in mind.

\section{PARIETAL}

Most of both parietals has been eroded off and all of their external surface is missing. However, the internal mold of the bone in the matrix retains most of the sutures (figs. 5, 10). The parietal of Chubutemys is a large rectangular element, contacting the frontal anteriorly and the postorbital anterolaterally. Posterolaterally, a suture with the squamosal can be made out on each side, but the postorbital-squamosal (or quadratojugal) suture is too damaged to be seen clearly.

Chubutemys differs significantly from the similar Dracochelys, as well as from the other 


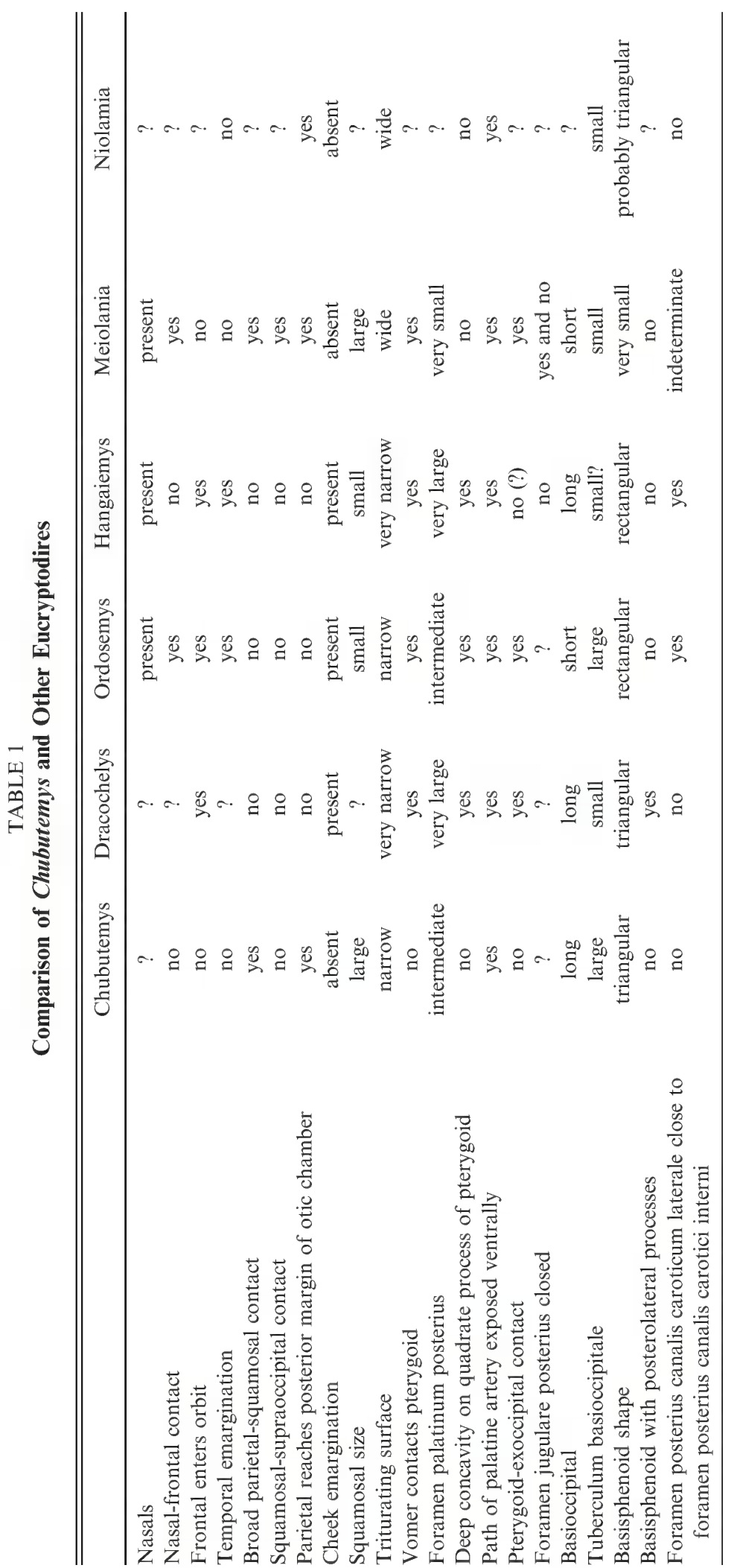


TABLE 2

Measurements of Type Skull of Chubutemys, MPEF-PV-1236 (in $\mathrm{mm}$ )

\begin{tabular}{lc}
\hline \hline $\begin{array}{l}\text { Midline length from premaxilla to posterior } \\
\text { margin of parietals }\end{array}$ & 97.0 \\
Midline length from premaxilla to occipital & 85.7 \\
$\quad$ condyle & 76.0 \\
Maximum width & $18.2^{\mathrm{a}}$ \\
Width between orbits & $23.3^{\mathrm{a}}$ \\
Width of right orbit & $10.1^{\mathrm{a}}$ \\
Height of right orbit & 13.2 \\
Width of internal nares & $37.7^{\mathrm{a}}$ \\
Maximum height at quadrate & 30.3 \\
\hline
\end{tabular}

a Damaged.

"sinemydids/macrobaenids", Judithemys, Sinemys, Ordosemys and Hangaiemys, in having no temporal emargination. The parietal of Chubutemys extends well posterior to the posterior edge of the otic chamber. The supraoccipital is present in part between the parietals, but the sutures are unclear. Meiolania has an extensive temporal roof, but this is the result of a large squamosal and a laterally expanded supraocciptal. The parietal in Meiolania is relatively small, nearly square, and much smaller than the parietal in Chubutemys. Nonetheless, the parietal of Meiolania does agree with Chubutemys in reaching the posterior edge of the otic chamber and broadly contacting the squamosal.

The skull roof in Macrobaena (Tatariniv, 1959) also lacks temporal emargination, but it is too poorly known for the composition of the skull roof to be determined from the literature. For this reason Macrobaena is not included in our data set and has not been included in other authors' data sets.

Near the posterior edge of the parietal in MPEF-PV1236 are the two atlantal neural arches, disarticulated from the atlas (fig. 10).

\section{JUGAL}

The jugal is present on the right cheek (figs. 8, 10), though not well defined, and is largely missing on the left. There is what appears to be the anterior contact with the maxilla and the posterior contact with the quadratojugal. The postorbital-quadratojugal contact is unclear, and some of the dorsal suture around the jugal is presumably with the postorbital. As interpreted, the jugal is a relatively large element, making up most of the cheek. There is no cheek emargination, and the jugal makes a slight posteroventral extension comparable to the one in Meiolania. Ordosemys, Dracochelys, and Hangaiemys have a cheek emargination and a much smaller jugal than that in Chubutemys.

\section{QUADRATOJUGAL}

It is likely that the bone area posterior to what we have identified as jugal on the right side of MPEF-PV1236 is the quadratojugal (fig. 10C), in which case it probably contacts the postorbital dorsally, but its relationships to the squamosal or anything else are unknown.

\section{SQuamosal}

Very little bone representing the squamosal is present on either side, but the mold in the matrix on the right side shows what appears to be the squamosal and its broad contact with the parietal (fig. 10A, C).

\section{Postorbital}

Much of the postorbital is present on the right side (figs. 8,10 ), and an internal mold of some of it is present on the left. Sutures are probably with the prefrontal anteriorly, the frontal anteromedially, the parietal medially, and presumably the squamosal and/or quadratojugal posteriorly. The lateral and ventral contacts, for example, with the jugal, are unclear.

\section{Premaxilla}

The anteriormost end of the skull is broken off and no premaxillary sutures can be seen. The break is about where a maxilla-premaxilla suture would be expected in Ordosemys or one of the other eucryptodires. On the ventral surface, there is a vomer suture at its anterior end and this is most likely with the premaxilla (fig. 10B). This would indicate a premaxilla close in size and shape to that in Ordosemys and Dracochelys. 

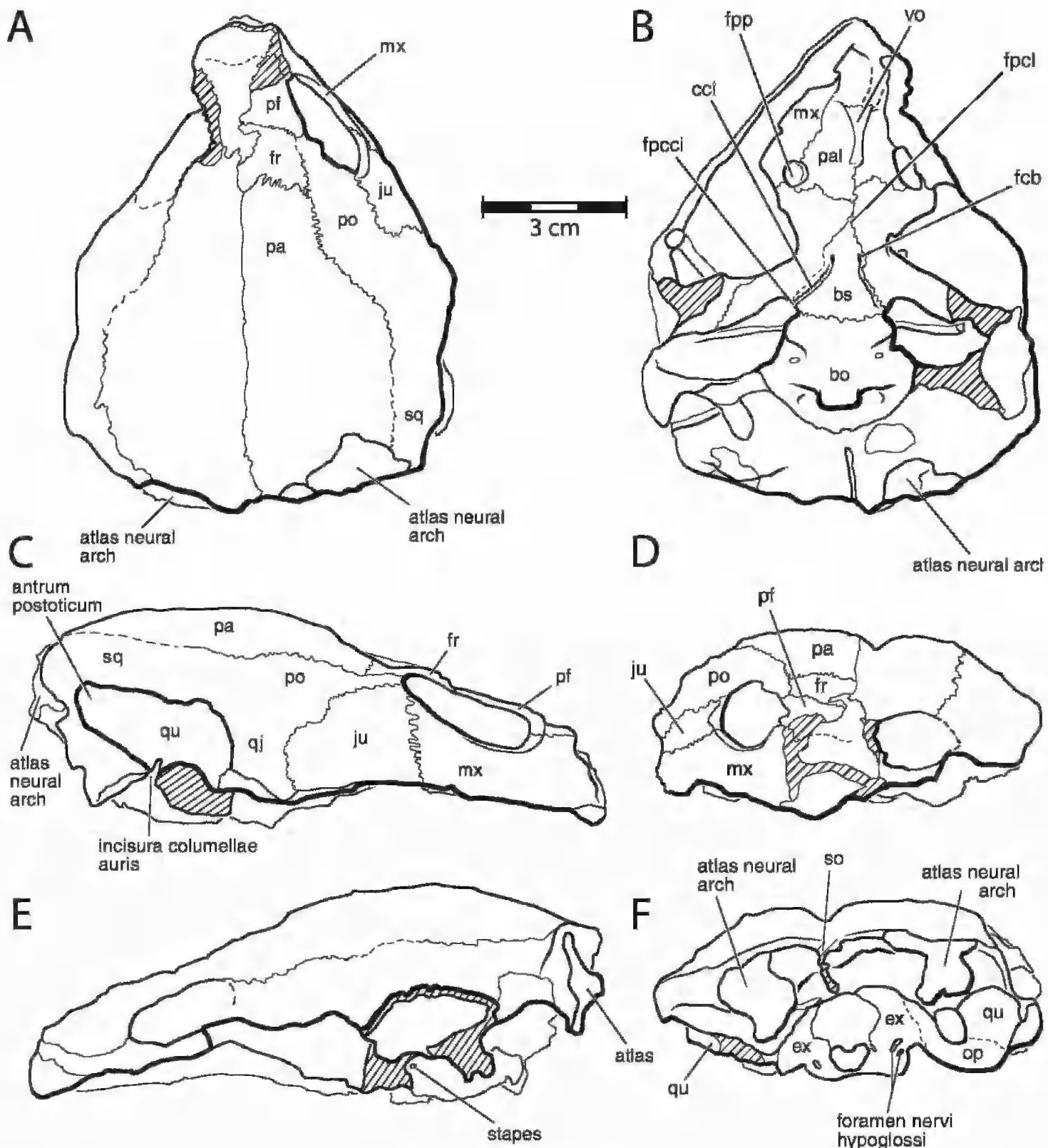

Fig. 10. Chubutemys copelloi, n. gen. et sp. MPEF-PV1236, holotype. Line drawings of skull views shown in figs. 2-6. A, Dorsal; B, ventral; C, right lateral; D, anterior; E, left lateral; F, posterior.

\section{Maxilla}

The maxilla (figs. $6,8,10$ ) is best preserved on the right side, but some of the triturating surface is present on the left. Its external surface is present on the right as well as most of its ventral surface.
The labial ridge of Chubutemys is a straight, narrow sheet, similar to that in Dracochelys, Ordosemys, and Hangaiemys. There is no evidence of the cusps seen near the premaxillary contact in Dracochelys. The depth of the ridge is similar to Ordosemys and Dracochelys. The labial ridge is low and 
parallels the lingual ridge as in Ordosemys, Dracochelys, and Hangaiemys. The width of the triturating surface in Chubutemys is very similar to that in Ordosemys, that is, wider than the very narrow surface of Hangaiemys and Dracochelys, but narrower than that in meiolaniids.

The apertura narium interna in Chubutemys is very similar in position and size to that in Ordosemys, Dracochelys, and Hangaiemys. The foramen palatinum posterius is unusually large in Hangaiemys and Dracochelys, but it is smaller, about as in Chelydra, in Chubutemys and Ordosemys. In Meiolania the foramen is unusually small.

\section{VOMER}

The vomer in Chubutemys (figs. 6, 10) is relatively well preserved, broken in the middle but with good contacts. The vomer in Chubutemys is similar to that bone in other non-polycryptodiran eucryptodires. Its contacts are with the premaxilla anteriorly, the prefrontal (questionably) anterolaterally, and the palatine laterally. In contrast to Dracochelys, Ordosemys, Hangaiemys, and Meiolania, there is no posterior contact with the pterygoid. The vomer in Meiolania is usually wide, forming the parasagittal choanal grooves characteristic of this genus. The vomer has a midline, sagittal ridge that appears to be relatively wide in Chubutemys as in Dracochelys, not narrow as in Hangaiemys and Ordosemys, although this could be the result of poor preservation.

\section{Palatine}

The palatine in Chubutemys (figs. 6, 10) is present on both sides and has sutures showing most of its limits. It has the usual cryptodiran contacts of vomer medially, pterygoid posteriorly, and maxilla laterally. An anterior prefrontal contact is likely but not clear. Chubutemys differs from Ordosemys, Dracochelys, Hangaiemys, and Meiolania because the palatines meet in the midline and are not separated by the vomer. The shape of the palatine is similar in Chubutemys, Dracochelys, Hangaiemys, and Ordosemys. The bone is much smaller in Meiolania.

\section{QuAdRATE}

The right quadrate in Chubutemys (figs. 6, $8,10)$ preserves the cavum tympani, but the processus articularis is broken off. The left quadrate is less complete, lacking much of the cavum tympani as well as the processus articularis. Quadrate sutures are generally unclear, but on the right side one can be interpreted as a quadratojugal and squamosal contact. In ventral view, the quadrate-pterygoid suture is visible on the right side as well as the contact with the squamosal and opisthotic.

As preserved, the cavum tympani in Chubutemys is very deep and has a large dorsal overhang. This condition, however, is probably exaggerated by dorsoventral crushing in this specimen. Nonetheless, the dorsal part of the cavum tympani probably was much deeper than the anterior area. The ventral area is missing. The dorsal area leads into the antrum postoticum, which is mostly missing, but appears to have been comparable in size and shape to that in Ordosemys. The incisura columellae auris is preserved almost completely on the right side and partially on the left. It is narrow but posteroventrally open as in Ordosemys and Dracochelys (unclear in Hangaiemys). In Meiolania it is similar but closed laterally to include the eustachian tube by approximation of the quadratojugal and quadrate. It is possible that this was also the case in Chubutemys, but the lateralmost parts of the quadrate are missing. The processus trochlearis oticum can be seen on both sides. It seems to be comparable in size to that in Ordosemys and Dracochelys.

Both stapes are preserved in place in Chubutemys from the incisura columellae auris to the fenestra ovalis. The stapes is thicker in Chubutemys than in Chelydra with a similarsized skull. The footplate is conical rather than disc-shaped, a feature of baenids, meiolaniids, and some trionychoids (see Gaffney, 1983: 449). It is unknown in the other eucryptodires compared here.

\section{EPIPTERYGOID}

A small section of what appears to be the epipterygoid is preserved on the right side 
anterodorsal to the cavum epipterygoidei, in its usual eucryptodiran position.

\section{PTERYGOID}

The pterygoid is preserved almost completely on both sides (figs. 6, 10). Its surface is eroded in some areas and some of the thin web of bone that usually stretches medially from the quadrate ramus has been lost on both sides, revealing the cavum acusticojugulare in ventral view. The pterygoid of Chubutemys meets the palatine anteriorly, the other pterygoid in a short suture anteromedially, the basisphenoid medially, and the quadrate posterolaterally. The pterygoid, along with the maxilla and palatine, forms the foramen palatinum posterius. The processus pterygoideus externus in Dracochelys is characteristically very large, but both processes are mostly missing in Chubutemys, and its size is unknown. In Dracochelys, Hangaiemys, and Ordosemys there is a deep fossa just posterior to the quadrate ramus of the pterygoid. Much of this area in Chubutemys has been eroded but enough is preserved to show that a deep fossa was absent, making Chubutemys more like Chelydra in this feature. Meiolania also lacks a fossa in this position. Ordosemys and Dracochelys also have a distinct ridge paralleling the bone margin laterally, presumed to be for pterygoideus muscle attachment. This ridge is absent in Chubutemys and also in Meiolania.

The medial margin of the pterygoid in Chubutemys contacts the basisphenoid, and on the right side the anterior part of this suture is expanded to form a foramen, just lateral to the midline. On the left side, the foramen is present but damaged by crushing. In Dracochelys this foramen was identified as the foramen caroticum laterale (Gaffney and Ye, 1992), being the entry of the palatine artery into the cavum cranii. Chubutemys appears to have this foramen in the identical position as it is in Dracochelys. In Hangaiemys and Ordosemys the basisphenoid is much shorter than in Chubutemys and Dracochelys, and the foramen is positioned farther posteriorly, close to the foramen caroticum basisphenoidale. The difference is due to a thin, posteromedial sheet of pterygoid that covers the basisphenoid in Hangaiemys and Ordosemys.

The term foramen caroticum laterale as currently used actually refers to both a more anterior foramen opening into the braincase floor and a more posterior foramen opening on the roof of the palate, with the canalis caroticus lateralis (Gaffney, 1979 and others) connecting them. Sukhanov (2000) used the term "foramen posterius canalis caroticus laterale" for the posterior foramen, and we have adopted that usage here.

\section{SUPRAOCCIPITAL}

Only a small part of the supraoccipital is preserved (figs. 7, 10). On the dorsal surface some of the bone on the midline portion of the temporal roof is probably supraoccipital. In occipital and ventral view a portion of the crista supraoccipitalis is visible. It is comparable in size and shape with those seen in other non-polycryptodiran eucryptodires. Although very little bone is present on the posterior part of the temporal roof, the internal mold of the ventral surface does show other sutures and there is no indication of a laterally expanded supraoccipital as seen in Meiolania.

\section{EXOCCIPITAL}

Both exoccipitals are preserved and some sutures are visible (figs. 7, 10). Laterally, the exoccipital contacts the opisthotic and ventrally the basisphenoid. As preserved there is no pterygoid contact as seen in Dracochelys, Ordosemys, and Meiolania. Hangaiemys seems to lack the contact, but it is hard to be sure. It is possible that Chubutemys had a pterygoidexoccipital contact because clearly some of the posterior portion of the pterygoid is missing due to damage. However, it is difficult to say how much is missing.

The foramen magnum in Chubutemys is about as wide as high, not as narrow as in Dracochelys and Ordosemys, but this could be due to crushing. The two foramen nervi hypoglossi can be seen on the right side and one on the left. The area is not well preserved, but it is possible that the medial margin of the foramen jugulare posterius is preserved on the 
right side. As preserved the foramen is not enclosed, but its margin could easily be missing. However, neither Dracochelys nor Ordosemys seems to have a definitive foramen jugulare posterius, so the situation is ambiguous. The condylus occipitalis has no sutures preserved on it, but it is presumed to be formed by the exoccipitals and basioccipital as is usual in cryptodires.

\section{BASIOCCIPITAL}

The basioccipital (figs. 6, 10) is nearly complete in MPEF-PV1236, but seems at least slightly eroded along its lateral edges. There is a clear anterior suture with the basisphenoid, but the exoccipital sutures are visible in only a few places. As preserved, there is no pterygoid contact as seen in Dracochelys. The basioccipital in Chubutemys is relatively long as in Hangaiemys and Dracochelys, not short as in Ordosemys, although this comparison is somewhat subjective. The tuberculum basioccipitale in Chubutemys is distinct as in Ordosemys, and much larger than in Dracochelys.

\section{Prootic}

Although both prootics are probably complete in MPEF-PV1236, they are mostly covered by matrix. The bone is best seen on the right side where the anterior surface of the otic chamber is exposed, but no sutures are apparent, so the bone is not identified in the figures. The processus trochlearis oticum is comparable in size to that in Dracochelys and Ordosemys. The foramen nervi trigemini, also presumably formed in part by the prootic, is visible on the right but no sutures can be seen. lts position and size are similar to Chelydra.

\section{OPISTHOTIC}

Most of both opisthotics are preserved in MPEF-PV1236, but sutures are visible only on the right side (fig. 10). Only the ventral and occipital surfaces of the opisthotic are visible in MPEF-PV1236; the dorsal surfaces are covered with matrix. The opisthotic in Chubutemys is basically similar to that in other cryptodires, as this bone does not vary much within this group. In ventral view it lies between the quadrate and squamosal laterally and the exoccipital medially. As preserved the floor of the cavum acustico-jugulare is largely missing. This reveals the stapes and the fenestra ovalis being formed posteriorly by the processus interfenestralis of the opisthotic. The fenestra ovalis is not visible in ventral view in other eucryptodires. Its visibility in Chubutemys may be due to missing bone in MPEF-PV1236. In MPEF-PV1236 the foramen externum nervi glossopharyngei is visible at the base of the processus interfenestralis as well as the foramen jugulare anterius.

\section{BASISPHENOID}

The entire basisphenoid is preserved and visible in ventral view in MPEF-PV1236 (fig. 10). Sutures are present for most of its margins. The basisphenoid is triangular and lies between the pterygoids anterolaterally. A posterior transverse suture is with the basioccipital. As preserved in Chubutemys the pterygoid does not reach the basioccipital as in Ordosemys, and the basisphenoid has a free lateral edge just anterior to its contact with the basioccipital. Hangaiemys (Sukhanov and Narmandakh, 1974; Sukhanov, 2000) seems to have a similar condition in which the pterygoid barely reaches the basioccipital. If the pterygoid were only slightly eroded it would produce a free edge for the basisphenoid.

Midway along the length of the basisphenoid is the paired foramen caroticum basisphenoidale (figs. 4, 10). In MPEF-PV1236 this foramen is preserved on both sides with a poorly preserved canalis caroticus internus extending posterolaterally from it. The canalis is only a poorly defined groove on the right, but on the left a small portion of floor is preserved showing that it was a canal (fig. 6). The canal closely follows the pterygoid-basisphenoid suture where that is visible. The foramen posterius canalis carotici interni is interpreted to lie at the posterior end of the groove, formed in or near the pterygoidbasisphenoid suture as in Dracochelys, Ordosemys, and probably Hangaiemys. In Meiolania and Niolamia (Gaffney, 1983) the canalis caroticus internus is deeper within the pterygoid and basisphenoid but still close to 

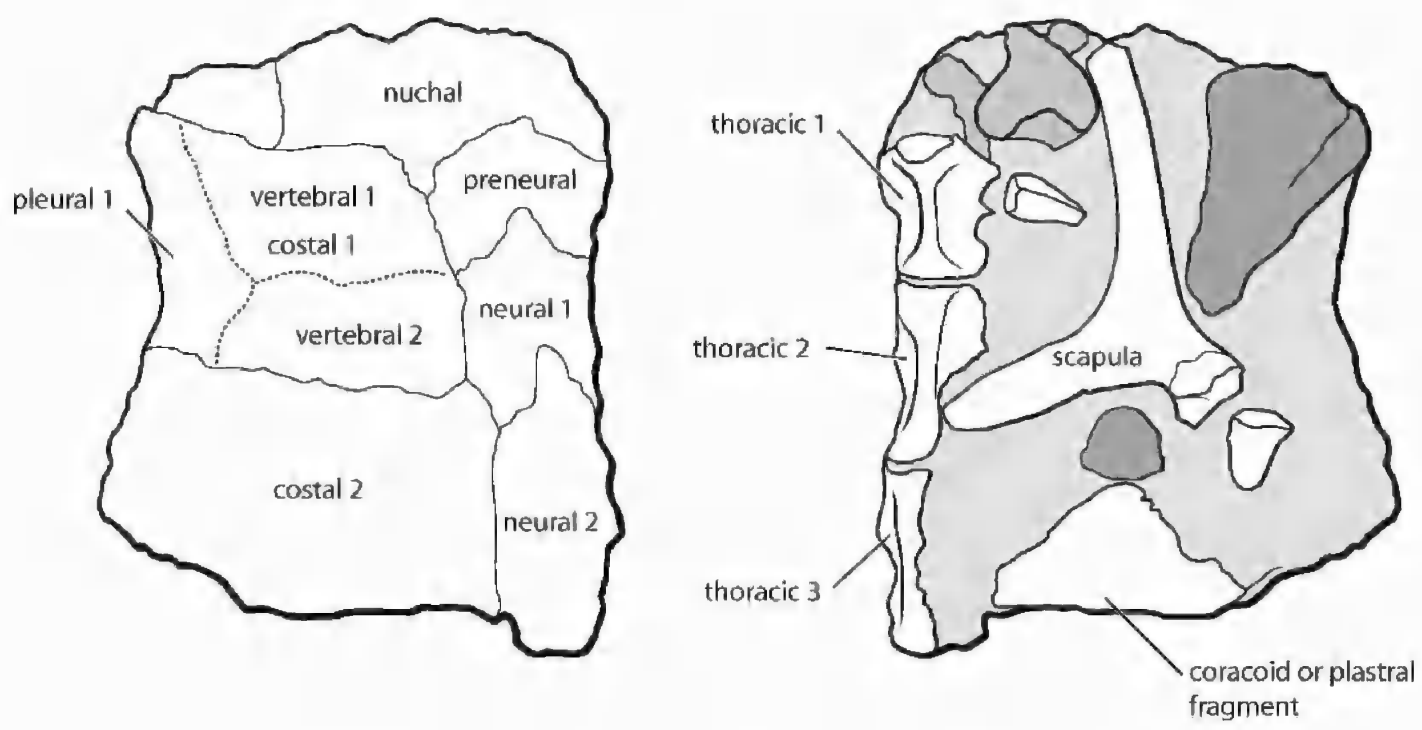

\section{matrix $\square$ cervical $8 \quad \square$ humerus}

Fig. 11. Chubutemys copelloi, n. gen. et sp. MPEF-PV1940. Anterior portion of carapace. Left, dorsal view; right, ventral view. Anterior to top of page. In dorsal view, solid lines are sutures, dotted lines are scale sulci. Cervical eight is shown in more detail in fig. 12.

the sutural contact of those bones. In Ordosemys, Dracochelys, Hangaiemys, and Chubutemys there is both an open foramen basisphenoidale and ventrally open foramen caroticum laterale, leading Gaffney (1996: 139) to suggest that the branching of the palatine artery from the carotid was unenclosed by bone. Gaffney $(1983,1996)$ also argued that the condition in Niolamia (and its modified form in Meiolania) was very similar to that in Dracochelys, now known in Ordosemys, Hangaiemys, and Chubutemys. The pterygoid of Niolamia (Simpson, 1938; Gaffney, 1983: fig. 60) is very similar to the pterygoid in Dracochelys and Chubutemys, apparently differing only in the greater thickness of the canalis caroticus internus floor in Niolamia. This is further evidence that the gap in the suture between the basisphenoid and pterygoid in Dracochelys and Chubutemys is the homologue of the intrapterygoid slit of meiolaniids, as suggested by Gaffney (1996).

\section{CARAPACE}

The left anterior fragment of a carapace (fig. 11) is preserved along with postcranial elements in MPEF PV1940. The dorsal surface consists of some bone along with the underlying mold of the missing bone. The medial ends of costals one and two, the posterior edge of the nuchal, neurals one and two, and a presumed preneural are present on the dorsal surface. The nuchal is relatively broad, similar to that in Ordosemys, Dracochelys, and other non-polycryptodire eucryptodires. Costals one and two also vary little among these taxa, and Chubutemys agrees with them. The neurals are not well preserved and the bone surface is eroded off, but sutures are visible. If correctly interpreted, Chubutemys has a preneural between the nuchal and neural one. Ordosemys (Brinkman and Peng, 1993a) is another non-polycryptodire eucryptodire with this element. In Ordosemys it is longer than wide; in Chubutemys it is wider than long.

The only dorsal surface preserved in MPEF PV1940 is in the area of the first costal. This shows sulci of the triple junction between vertebral scale one and two and pleural scale one. The position of this junction in Chubutemys is very similar to that in Ordosemys and the other early eucryptodires. The first vertebral does not seem to be much 
larger than the second as in these forms and Kirgizemys. The bone surface as preserved is smooth, lacking a textured pattern. The sulci are broadly incised, forming wide troughs.

On the ventral surface of MPEF PV1940 are the first three thoracic vertebrae, the eighth cervical, the left humerus and scapula, and a flat bone fragment that could be a piece of plastron or coracoid. The first thoracic has an anterior central articulation facing anteriorly as in Ordosemys, Xinjiangchelys, Meiolania, Sinemys, and Dracochelys, and it is interpreted as the primitive cryptodiran condition (Gaffney, 1996). The rib head for this centrum is visible, but the distal part of the rib is covered by matrix, thus preventing determination of its length.

\section{Cervical Eight}

An eighth cervical vertebra (figs. 11, 12) is in articulation in the partial carapace, MPEF PV1940. As the eighth cervical figures importantly in previous analyses of eucryptodire relationships, it is important to describe that bone in Chubutemys. The eighth cervical is also known in Dracochelys (Brinkman, 2001), Ordosemys (Brinkman and Peng, 1993a), Otwayemys (Gaffney et al., 1998), Sinemys (Brinkman and Peng, 1993b), Xinjiangchelys (Kaznyshkin et al., 1990), and Meiolania (Gaffney, 1985, 1996). Phylogenetic analyses using eighth cervical morphology that include discussion of characters are Gaffney (1996) and Brinkman and Wu (1999). The eighth cervical of MPEF PV1940 is not completely preserved. Figure 12 has been partially restored by assuming bilateral symmetry. The centrum, transverse processes, and right zygapophyses are visible, but nothing of the neural arch or spine can be seen. The ventral edge of the centrum is eroded off and there has been dorsoventral crushing. The crushing has pressed the postzygapophyses so far ventrally that the neural canal is nearly obliterated. Anteriorly, the crushing is much less and may be nonexistent, but this is difficult to determine.

The eighth cervical of MPEF PV1940 as preserved is generally similar to those in other early Cretaceous eucryptodires. The centrum is biconvex as in Dracochelys, Ordosemys.
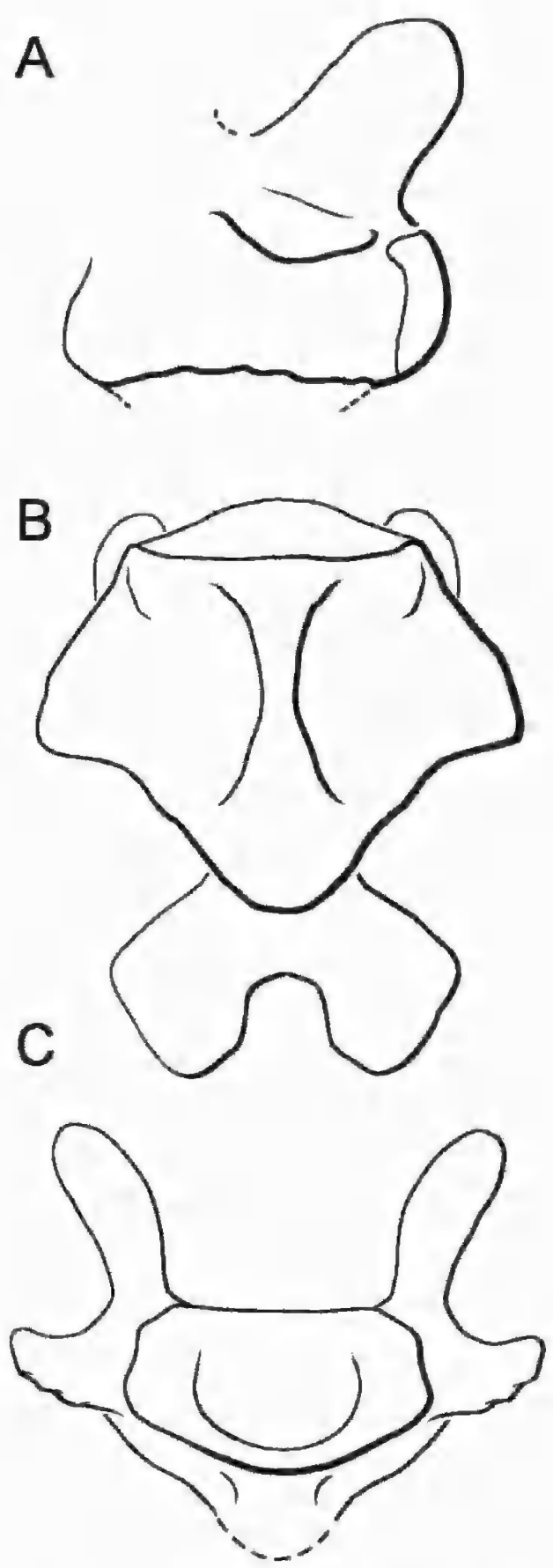

Fig. 12. Chubutemys copelloi, n. gen. et sp. MPEF-PV1940, Partially restored eighth cervical vertebra. A, Right lateral; $\mathbf{B}$, ventral, anterior to top of page; $\mathbf{C}$, anterior. 
Otwayemys, and Sinemys, in contrast to the procoelous condition of Meiolania and the Polycryptodira. The posterior articulation in Chubutemys is relatively narrow and hemispherical, while the anterior articulation is much wider. This condition can also be seen in Otwayemys, but the wider distribution of this feature is unclear. The transverse processes in Chubutemys are single as in Chelydra and the Polycryptodira, not double as in Dracochelys, Otwayemys, Ordosemys, Sinemys, and Meiolania. The transverse process in Chubutemys is also placed more anteriorly than the middle of the centrum. This condition is also as in the above genera and the Polycryptodira. There is no evidence of cervical ribs. The ventral surface of the centrum is eroded, and the presence or absence of a keel or process is not determinable.

The prezygapophyses in Chubutemys are only represented by the right one, and it is placed much more laterally than in Otwayemys, Dracochelys, Ordosemys, and Meiolania. This may be due to deformation. Its position could have been very similar to those in Ordosemys and Dracochelys, which are farther apart than in Otwayemys. The postzygapophyses in Chubutemys are also widely placed as in Ordosemys, not narrow as in Otwayemys. The eighth cervical in MPEF PV1940 is positioned anterior and lateral with respect to the first dorsal. It also underlies the nuchal. There is no sign on the nuchal of a neural spine pushed through or crushed beneath it. The implication is that Chubutemys does not have a tall neural spine as in Otwayemys and Meiolania, but this is just a guess.

\section{PHYLOGENETIC ANALYSIS}

Chubutemys is a cryptodire similar to other cryptodires that have been referred to as "sinemydids" and "macrobaenids" (see Gaffney and Yeh, 1992; Gaffney, 1996; Brinkman and Peng, 1993a; Brinkman and Wu 1999; Brinkman, 2001; Sukhanov, 2000, for references), and it is among these extinct cryptodire groups that its relationships are to be sought. The present analysis is based on an analysis developed in 1992 in a joint effort by Don Brinkman, Gene Gaffney, Howard Hutchison, and Peter Meylan. The major part of this analysis was published in Gaffney (1996). Once again, the senior author is very grateful to his three colleagues for sharing their knowledge. Analyzing relationships of the extinct eucryptodires is hampered by the fact that the terminal taxa being analyzed are something of a moving target. Many named taxa are inadequately described in the literature but are known firsthand by some workers, making corroboration of some published character distributions more difficult than usual.

Although the matrix of 111 characters (appendix 1) is based on the 40 characters in Gaffney (1996), it has obviously been greatly altered by the addition of new ones. In Gaffney (1996) the specific-level taxa in the family Meiolaniidae were analyzed separately from the family Meiolaniidae among turtles, so two data sets were used. We have incorporated some of the characters from the within-group data set here. Brinkman and $\mathrm{Wu}$ (1999) made significant additions, and their characters are also added here (except for parsimony uninformative ones due to nonoverlapping terminal taxa). Characters are also added from Rougier et al. (1995) and Gaffney et al. (2006).

Hirayama et al. (2000) proposed a cladogram showing eucryptodires to be nonmonophyletic, with meiolaniids allied with Mongolochelys and outside most other cryptodires. The Hirayama et al. (2000) cladogram is based on a 69 character data set, including the 40 characters from Gaffney (1996), modified in Gaffney et al. (1998), and characters from Parham and Hutchison (2003). We have used at least a version of all the characters in the Hirayama et al. (2000) data set that are parsimony-informative. Because we have deleted some terminal taxa (that in our opinion are not firmly based) from Hirayama et al. (2000), some characters from Hirayama et al. (2000) that were parsimony-informative in that analysis are no longer parsimony-informative in our analysis and have been deleted. A few characters have been altered either in definition or distribution. The altered characters relevant to meiolaniid relationships in particular are as follows:

1. "(10) Prominent enlargement of squamosal reaching supraoccipital." This character is 
unchanged here. but we have added another character, supraoccipital with horizontal plate, to reflect the different conditions of the contact. In both Mongolochelys and meiolaniids, there is a large squamosal forming most of a posteriorly directed temporal margin. However, in Meiolania much of this margin is formed by a horizontal plate of the supraoccipital, which is absent in Mongolochelys. In the latter the squamosals meet on the midline, a condition not seen in meiolaniids.

2. Hirayama et al. (2000) united meiolaniids and Mongolochelys on the common presence of "(13) Prominent lingual ridge on maxilla", or "accessory ridge on the triturating surface" in our usage. Although this ridge is present in Meiolania and Ninjemys, the sister taxon of these. Niolamia. lacks the ridge. In the cladogram and data set for Meiolaniidae developed by Gaffney (1996) and used here, the absence of the ridge is primitive for Meiolaniidae and does not unite Meiolaniidae and Mongolochelys.

3. Another character of more general distribution that breaks up the Eucryptodira in Hirayama et al. (2000) is the "lower cheek emargination". In Hirayama et al. (2000) the complete absence or presence of a shallow cheek emargination is one state, but we see three states: $0=$ absent, shallow, with a large jugal: 1 = absent, shallow, with a large quadratojugal; 2 = moderate to deep. We have used these to reflect what we see as a significant difference when the solid cheek is formed by a large jugal as in Proganochelys, Australochelys, Kayentachelys, as well as Mongolochelys. This condition is common and seems to be primitive at the level of Testudines as well as Cryptodira. Meiolania has a solid cheek formed in part by an unusually large quadratojugal, which seems to be a different character state. This state may be best interpreted as the secondary filling of an emarginate cheek.

4. We have also used four rather than three states for the Hirayama et al. (2000) "Posterior temporal emargination" character. We have added a state, unique to meiolaniids for a fully covered skull roof, but with an unusually small parietal, a condition that is different from the much larger parietal seen in Proganochelys and other non-Casichelydians as well as in the extensively roofed Mongolochelys, Kallokibotion, and Chubutemys. The implication of the unique cheek and temporal roof structure in meiolaniids is that these areas may be secondarily solid from a more emarginated ancestor, similar to the conditions in taxa such as Dracochelys and Ordosemys

5. The Hirayama et al. (2000) character "(34) Cervical ribs of large size" also breaks up the Eucryptodira of Gaffney and other authors. Gaffney and others have used the simple presence or absence of cervical ribs as a character. The problem here is that cervical ribs in turtles show a great deal of variation, much of it described in Gaffney $(1985,1990)$, Brinkman and Peng (1993a). and Brinkman and Nicholls (1993), with a discussion of the problem in Gaffney (1996: 149). Hirayama et al. (2000) tried to use some of this diversity, but as discussed previously we think that the diversity does not show discrete states. It is true that there is a considerable difference in the relatively large ribs of Proganochelys (Gaffney, 1990) and the small ribs of some later cryptodires, such as baenids. However, the ribs in Meiolania (Gaffney 1985, 1990) do not agree with the morphology of the ribs in Proganochelys and are, in fact, unique among turtles in shape, as well as in their relative size. Therefore, we use only the presence/absence of ribs and not their size or other aspects of morphology.

Corrections to the data matrix in Gaffney et al. (1998) for characters referring to Hangaiemys are from Parham and Hutchison (2003). Parham and Hutchison (2003) also changed some characters for Judithemys (the unnamed TMP 87.2.1 of Gaffney, 1996), However, the senior author has corroborated some of the earlier codings and thinks that the original states for characters 3 (visible on broken edge of prefrontal on right side) and 18 (sutures visible on left side) are correct, Parham and Hutchison (2003) also change characters 4 and 5 in appendix 1 , but this may be an crror. We use the original codings from Gaffney (1996). Character 25. presence of chevrons, was reported absent by Parham and Hutchison (2003), but chevrons are clearly present on the anterior caudals preserved in TMP 87.2.1 (Parham and Hutchison, 2003: fig. 8D). In order to clarify the senior author's 

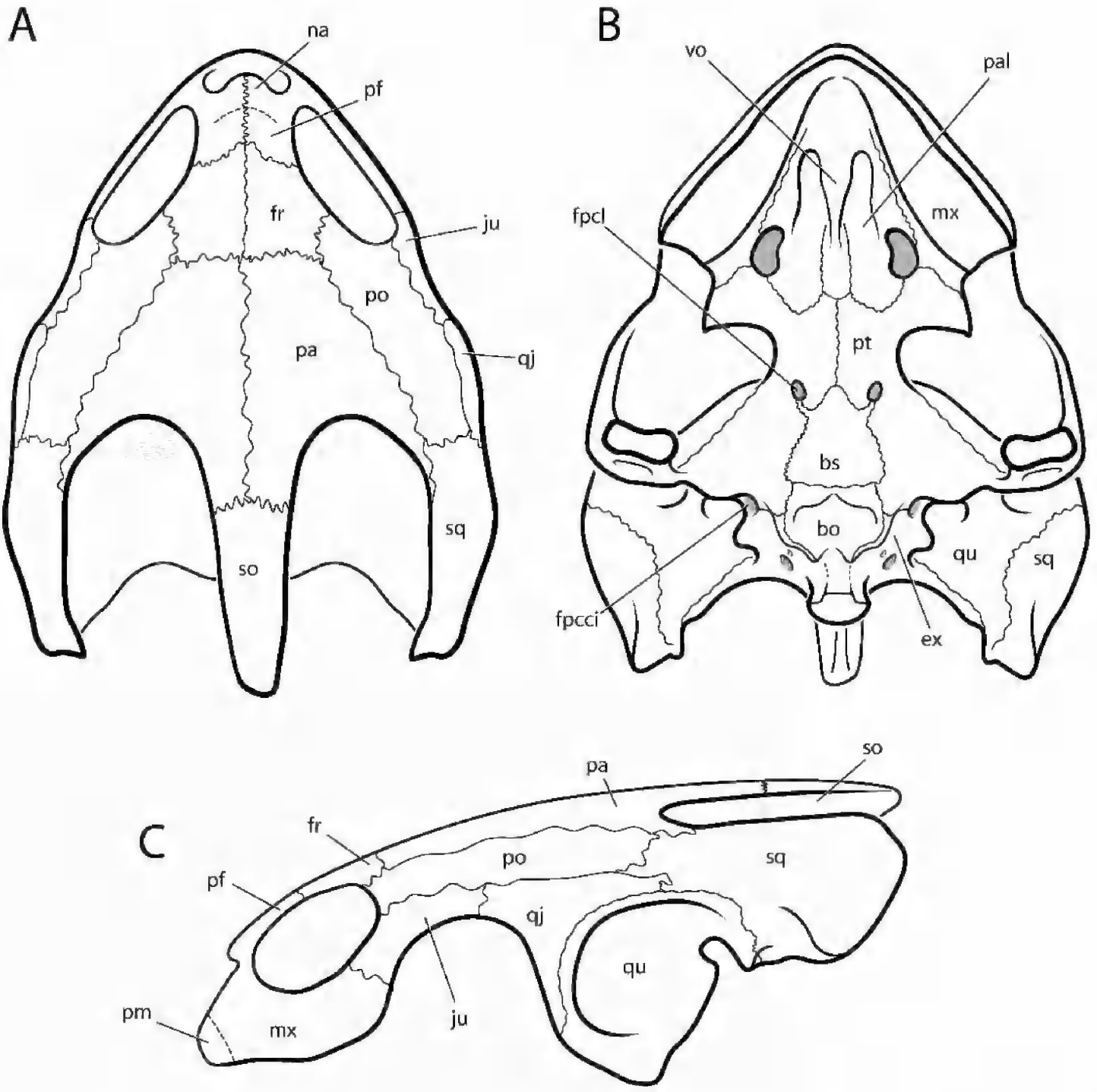

Fig. 13. Judithemys sukhanovi Parham and Hutchison, 2003, TMP 87.2.1. Partially restored views of the skull. A, Dorsal; B, ventral; C, left lateral.

interpretations of the skull of Judithemys (TMP 87.2.1), a set of partially restored views are provided as fig. 13.

The terminal taxa used here are mostly the "usual suspects" from Gaffney (1996), with some additions. As it became apparent that Chubutemys may be related to meiolaniids and that the position of meiolaniids has been called into question by Hirayama et al. (2000), the better known meiolaniid taxa were added to the analysis. The discovery of associated postcranial material of Solnhofia
(Joyce, 2000; see also Broin, 1994; Lapparent de Broin et al., 1996) has allowed this taxon to be added. On the other hand, the relationships of the living cryptodire groups are beyond the scope of this analysis, and only a few characters and larger, more inclusive taxa are used. The molecular evidence that the family Trionychidae is the sister taxon to all other living cryptodires is a hypothesis well beyond the scope of this paper, and we continue to use Trionychoidea. We do not think that this lumping of the recent taxa significantly affects 


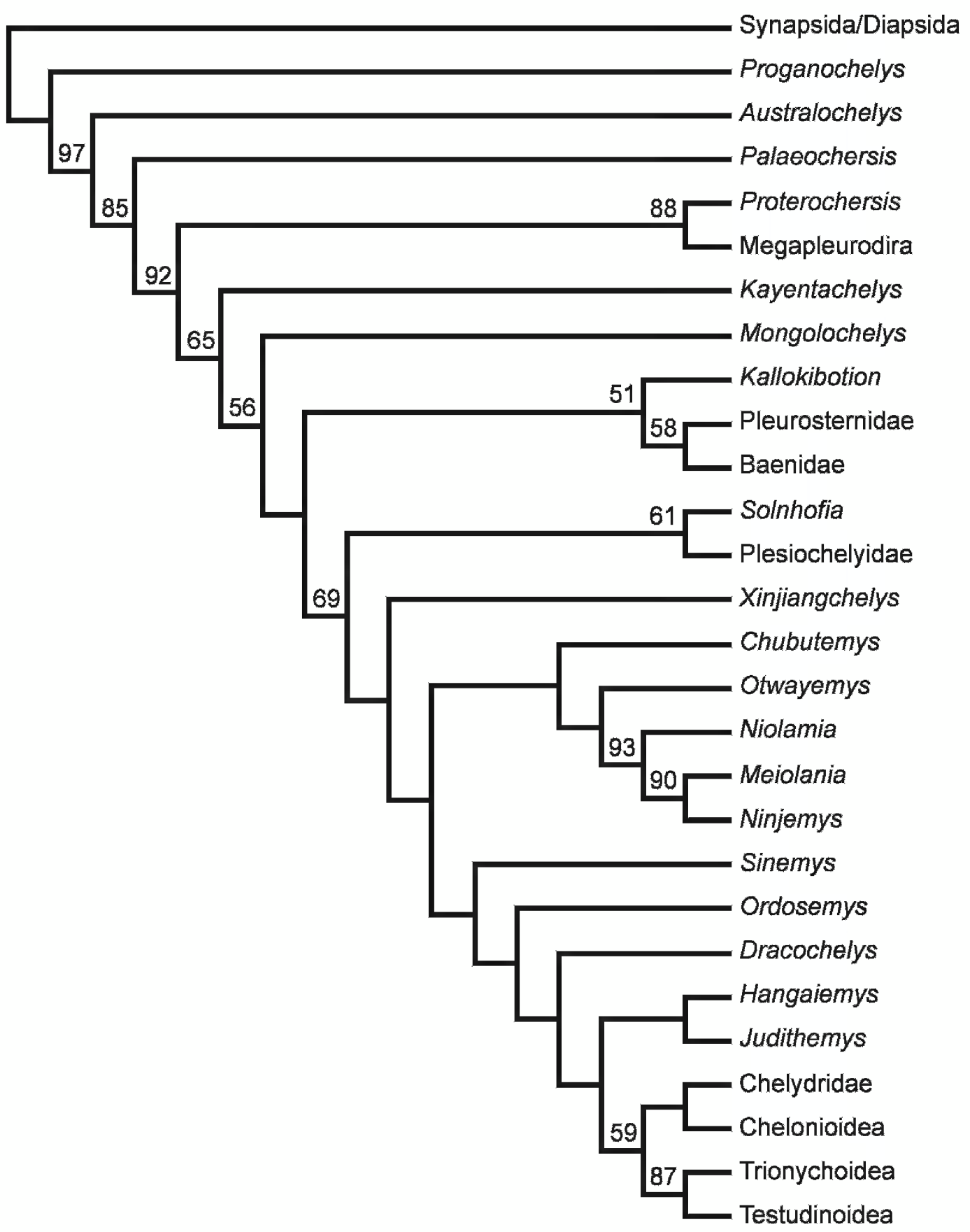

Fig. 14. Most parsimonious cladogram (MPC) based on data set shown in appendix 2. Numbers at nodes show result of bootstraping. Higher taxon names are as in Gaffney (1996).

cladograms of the extinct cryptodires we have chosen.

The phylogenetic analysis corroborates the eucryptodiran nature of meiolaniids and contradicts the hypothesis of Hirayama et al.
(2000). It also supports monophyly of the Centrocryptodira of Gaffney (1996), which has formed central articulations as one of its synapomorphies. The Sinemydidae of Gaffney (1996), supported by the biconvex eighth 
cervical in the earlier analysis, is not supported in the present analysis; instead, the extinct eucryptodire taxa often referred to as "sinemydids" and/or "macrobaenids" are resolved as a paraphyletic group of successive sister taxa to the Polycryptodira. The biconvex eighth cervical in this resolution becomes a synapomorphy for Centrocryptodira, lost in Meiolaniidae, Judithemys, (?Hangaiemys), and most of the Polycryptodira. The Centrocryptodira is also supported by the biconvex fourth cervical, which does occur in meiolaniids, as well as in the other Centrocryptodira, except Sinemys and trionychoids. The number of unambiguous synapomorphies and the bootstrap test (fig. 14) show Cryptodira and Eucryptodira to be well supported, but the resolution of extinct cryptodires breaks down in bootstrapping. Nonetheless, the most parsimonious tree (fig. 14) shows six unambiguous synapomorphies for the node containing Polycryptodires, Judithemys, Hangaiemys, Dracochelys, Sinemys, and Ordosemys. The particularly interesting result of this data set resolution is that the sister taxon to the above listed group consists of the meiolaniids plus Otwayemys and the subject of the present paper, Chubutemys. This is a little surprising because Chubutemys is similar to Dracochelys in much of its skull. It also does not rely on the fully roofed skull found in both Chubutemys and meiolaniids, because this is interpreted here as separate characters in these two taxa, and is not used as a character uniting Chubutemys and meiolaniids. A previous analysis of the Early Cretaceous Australian cryptodire Otwayemys (Gaffney et al., 1998) allied that form with meiolaniids, and the present analysis also found that relationship, adding Chubutemys as well.

Neither Chubutemys nor Otwayemys is strongly supported as a sister taxon to meiolaniids, but the most problematic element of this resolution is that both taxa have lots of missing data: Chubutemys, 49\%; Otwayemys, $68 \%$. PAUP fills in the missing characters consistent with the most parsimonious cladogram (MPC), which probably masks contradictory characters. There is only one unambiguous character uniting Chubutemys with meiolaniids, and that is the prefrontal-postorbital contact that prevents orbital exposure of the frontal. This is actually a rare character among the extinct cryptodire groups; it occurs in Mongolochelys and Polycryptodira, but it is indeterminate in Otwayemys. The sole character uniting Otwayemys and meiolaniids is the transverse process of the cervicals in the middle of the centrum, which is absent in all other Centrocryptodira except Dracochelys.

One could argue that the solid temporal roof of Chubutemys is the primitive condition for meiolaniids. The large parietal of Chubutemys certainly seems to be the primitive condition for cryptodires, although many Paracryptodira and Plesiochelyidae have some degree of emargination. Within Eucryptodira, only meiolanids and Chubutemys (outside a few Polycryptodira) have a fully roofed skull, and the present MPC suggests this may not be a homoplasy. However, if the meiolaniid condition is re-coded as " 0 " (agreeing with Mongolochelys and Kallokibotion), the same MPC results.

The carotid morphology of Chubutemys makes a good primitive condition for meiolaniids. Jamniczky et al. (2006) gave a summary of carotid canal hypotheses (see also Jamniczkyand Russell, 2004) and proposed an evolutionary progression consistent with our character states. The enclosed canalis caroticus internus posterior to the foramen basisphenoidale has been divided into two character states by Gaffney (1996), Gaffney et al. (1998), and Parham and Hutchison (2003), among others. One state is a thin or partial floor and the other is a thick floor. The senior author now thinks that this might be better changed to present/absent. After looking at a large number of specimens, both recent and fossil, the distinction is beginning to become blurred with a number of specimens within some species showing a fair amount of variation. However, changing the data set to present/absent results in the same MPC. For meiolaniids the carotid is embedded deeply in the pterygoid in Meiolania, but it is just covered by it in Niolamia (= Crossochelys, see Simpson, 1938: fig. 7), so a thin condition is probably primitive for the group.

The morphology of the canalis caroticus lateralis, the presumed path of the palatine artery, in Chubutemys is also primitive for the condition in meiolaniids. In Chubutemys and 
Dracochelys there is a step in the basisphenoid-pterygoid suture that opens up on each side very close to the midline to form the foramen posterius canalis caroticus laterale (the posterior opening of the foramen caroticum laterale), the presumed entry point of the palatine artery into the skull. In these two taxa the two openings form a V-shaped suture at the apex of the basisphenoid. In Hangaiemys (Sukhanov, 2000) the pterygoid-basisphenoid shelf forming the ventral margin of the foramen posterius canalis caroticus laterale is transverse rather than V-shaped, but it is otherwise apparently very similar. However, in Sinemys, Judithemys, and Ordosemys there is no shelf or foramina at the apex of the basisphenoid; instead, the foramen posterius canalis caroticus laterale is placed more laterally from the midline and more posteriorly. Although it is still formed by both pterygoid and basisphenoid, the basisphenoid is exposed as a short anterolateral process reaching the foramen posterius canalis caroticus laterale. The foramen is also a more oval foramen rather than the slit seen in Dracochelys and Chubutemys. The disarticulated pterygoid of Niolamia (AMNH 3161) figured by Simpson (1938: fig. 7) is clearly very similar to the pterygoid in Chubutemys and Dracochelys (and probably Hangaiemys, although the senior author has not seen this material). The primitive nature of the Niolamia (= Crossochelys Simpson) pterygoid was argued by Gaffney (1983: fig. 60). However, even in Meiolania platyceps, the likely homology of the meiolaniid intrapterygoid slit with the foramen posterius canalis caroticus laterale and canalis caroticus lateralis in the extinct eucryptodires is substantiated by comparison of fig. 55 (upper) in Gaffney (1983) showing Meiolania with figure 6A, C in Brinkman and Peng (1993a) showing Ordosemys. These figures show that the intrapterygoid slit in Meiolania actually has paired canals lying laterally formed by basisphenoid and pterygoid, as in Ordosemys and other non-polycryptodiran eucryptodires.

Therefore, Chubutemys provides further evidence that meiolaniids are related to "basal" eucryptodires or "sinemydids/macrobaenids", that is, eucryptodires outside the Polycryptodira. The basicranial morphology of meiolaniids, rather than being a unique feature of the group, is instead a modified state of the morphology seen in such "sinemydids/macrobaenids" as Chubutemys, Dracochelys, Ordosemys, and Sinemys.

Chubutemys shows that terrestrial eucryptodires were present in South America in the Cretaceous, as they were in North America, Asia, and Australia. At present, the distribution of the (probably paraphyletic) non-polycryptodiran eucryptodires seems to be relatively widespread: North and South America, central Asia, and Australia, but apparently not Africa (although the record is poor) or Europe. Chubutemys itself, if it does prove to be a meiolaniid sister taxon, would represent the Mesozoic distribution of the more restricted monophyletic group in Australia and South America that evolved into the meiolaniids with their characteristic skull roof synapomorphies. Others of the paraphyletic "sinemydids/macrobaenids" were more closely related to the living eucryptodires, the Polycryptodira.

\section{ACKNOWLEDGMENTS}

The senior author acknowledges the support of the Department of Paleontology, American Museum of Natural History, during the course of this project. We greatly appreciate the help of Juliana Sterli, Guillermo Rougier, Ren Hirayama, and an anonymous reviewer for improving the paper. The figures were done by Steve Morton (figs. 5-9), Aysha Venjara (figs. 10, 11, 12), and Frank Ippolito (figs. 4, 13), with final grooming on all figures by Frank Ippolito. We are very grateful to them all. We thank Judy Galkin for typing and bibliographic help. We also thank Maria Copello, Ruben Cuneo (Director of the Museo Paleontologico Egidio Feruglio), Peter Trusler, Pablo Puerta, Maxi Iberleucha, and Roberto Bianchi (mapping geologist, Comisión Nacional de Energía Atómica). The National Geographic Society (grant 5187-94) and the Australian Research Council provided funding for the fieldwork. The Comisión Nacional de Energía Atómica provided field housing for staff during the fieldwork. This paper was submitted on October 6, 2006, and was accepted September 24, 2007. 


\section{REFERENCES}

Brinkman, D.B. 2001. New material of Dracochelys (Eucryptodira: Sinemydidae) from the Junggar Basin, Xinjiang, People's Republic of China. Canadian Journal of Earth Sciences 38: $1645-1651$

Brinkman, D.B., and E.L. Nicholls. 1993. The skull of Neurankylus eximius (Testudines: Baenidae) and a reinterpretation of the relationships of this taxon. Journal of Vertebrate Paleontology 13: 273-281.

Brinkman, D.B., and J.-H. Peng. 1993a. Ordosemys leios, n. gen., n. sp., a new turtle from the early Cretaceous of the Ordos basin, Inner Mongolia. Canadian Journal of Earth Sciences 30: 2128-2138.

Brinkman, D.B., and J.-H. Peng. 1993b. New material of Sinemys (Testudines, Sinemydidae) from the early Cretaceous of China. Canadian Journal of Earth Sciences 30: 2139-2152.

Brinkman, D.B., and Xiao-Chun Wu. 1999. The skull of Ordosemys, an early Cretaceous turtle from Inner Mongolia, People's Republic of China, and the interrelationships of Eucryptodira (Chelonia, Cryptodira). Paludicola 2(2): 134-147.

Broin, F. de. 1987. The late Cretaceous fauna of Los Alamitos, Patagonia, Argentina. Part IV. Chelonia. Revista del Museo Argentino de Ciencias Naturales, Paleontologia 3(3): 131-178.

Broin, F. de. 1994. Données preliminaries sur les chéloniens du Tithonian inférieur des calcaires lithographiques de Canjuers (Var, France). Geobios 16: 167-175.

Broin, F. de., and M. de la Fuente. 1993a. Les tortues fossiles d'Argentine: première synthèse. Documents des Laboratoires de Géologie de la Faculté des Sciences de Lyon 125: 73-84.

Broin, F. de., and M. de la Fuente. 1993b. Les tortues fossiles d'Argentine: synthèse. Annales de Paléontologie 79(3): 169-232.

Carpenter, J.M. 2003. Critique of pure folly. The Botanical Review 69: 79-92.

Codignotto, J., F. Nullo, J. Panza, and C. Proserpio. 1978. Estratigrafia del Grupo Chubut entre Paso de Indios y Las Plumas, Provincia del Chubut, Argentina. VII Congreso Geologico Argentino, Neuquén (9-15 abril 1978), Actas 1: 471-480.

Cortiñas, J.S. 1996. La cuenca de SomuncuráCañadón Asfalto: sus límites, ciclos evolutivo del relleno sedimentario y posibilidades exploratorias. XIII Congreso Geológico Argentino y III Congreso de Exploración de Hidrocarburos, Actas 1: 147-163.
De Queiroz, K., and J. Gauthier. 1992. Phylogenetic taxonomy. Annals and Reviews of Ecology and Systematics 23: 449-480.

Fernandez, M.S., and M.S. de la Fuente. 1993. Las Tortugas Casiguelidias de las Calizas Litograficas Titonianas del Area Los Catutos, Neuquen, Argentina. Ameghiniana 30(3): 283-295.

Figari, E.G., and S.F. Courtade. 1993. Evolución tectosedimentaria de la Cuenca de Cañadón Asfalto, Chubut, Argentina. XII Congreso Geológico Argentino y II Congreso de Exploración de Hidrocarburos, Actas 1: 66-77.

Fuente, M.S. de la., and M.S. Fernandez. 1992. Un Nuevo Resto de Meiolaniidae (Chelonii: Cryptodira) del Terciario Temprano de Patagonia. Acta Zoologica Lilloana 41: 365-369.

Gaffney, E.S. 1972. An illustrated glossary of turtle skull nomenclature. American Museum Novitates 2486: 1-33.

Gaffney, E.S. 1979. Comparative cranial morphology of recent and fossil turtles. Bulletin of the American Museum of Natural History 164: 65-375.

Gaffney, E.S. 1983. The cranial morphology of the extinct horned turtle, Meiolania platyceps, from the Pleistocene of Lord Howe Island, Australia. Bulletin of the American Museum of Natural History 175: 361-480.

Gaffney, E.S. 1984. Historical analysis of theories of chelonian relationship. Systematic Zoology 33: 283-301.

Gaffney, E.S. 1985. The cervical and caudal vertebrae of the cryptodiran turtle, Meiolania platyceps, from the Pleistocene of Lord Howe Island, Australia. American Museum Novitates 2805: 1-22.

Gaffney, E.S. 1990. The comparative osteology of the Triassic Turtle Proganochelys. Bulletin of the American Museum of Natural History 194: $1-263$.

Gaffney, E.S. 1996. The postcranial morphology of Meiolania platyceps and a review of the Meiolaniidae. Bulletin of the American Museum of Natural History 229: 1-165.

Gaffney, E.S., L. Kool, D.B. Brinkman, T.H. Rich, and P. Vickers-Rich. 1998. Otwayemys, a new cryptodiran turtle from the early Cretaceous of Australia. American Museum Novitates 3233: $1-28$.

Gaffney, E.S., H. Tong, and P. Meylan. 2006. Evolution of the side-necked turtles: the families Bothremydidae, Euraxemydidae, and Araripemydidae. Bulletin of the American Museum of Natural History 300: 1-698.

Gaffney, E.S., and X. Ye. 1992. Dracochelys, a new cryptodiran turtle from the early Cretaceous of 
China. American Museum Novitates 3048: $1-13$.

Gasparini, Z., and M. Fernandez. 1997. Tithonian marine reptiles of the eastern Pacific. In J.M. Callaway and E.L. Nicholls (editors), Ancient marine reptiles: 435-450. Academic Press: San Diego, CA.

Hirayama, R. 1998. Oldest known sea turtle. Nature 392: 705-708.

Hirayama, R., D.B. Brinkman, and I.G. Danilov. 2000. Distribution and biogeography of nonmarine Cretaceous turtles. Russian Journal of Herpetology 7(3): 181-198.

Jamniczky, H.A., D.B. Brinkman, and A.P. Russell, 2006. Phylogenetic implications of turtle cranial circulation: a review. In I.G. Danilov and J.F. Parham (editors), Fossil turtle research, vol. 1. Russian Journal of Herpetology 13(suppl.): 84-92.

Jamniczky, H.A., and A.P. Russell. 2004. Cranial arterial foramen diameter in turtles: a quantitative assessment of size-independent phylogenetic signal. Animal Biology 54: 417-436.

Joyce, W.G. 2000. The first complete skeleton of Solhofia parsonsi (Cryptodira, Eurysternidae) from the Upper Jurassic of Germany and its taxonomic implications. Journal of Paleontology 74: 684-700.

Joyce, W.G., J.F. Parham, and J.A. Gauthier. 2004. Developing a protocol for the conversion of rank-based taxa named to phylogenetically defined clade names, as exemplified by turtles. Journal of Paleontology 78: 989-1013.

Kaznyshkin, M.N., L.A. Nalbandyan, and L.A. Nessov. 1990. [Middle and Late Jurassic turtles of Fegana (Kirghiz USSR).] Yezhegodnik Vsesoyuznogo Paleontologicheskogo Obshchestva [Annals of the All-Union Palaeontological Society] 32: 185-204. (in Russian).

Lapparent de Broin, F. de. 1993. Une faune continentale a vertébrés dans le Lutétien Supérieur de Guitrancourt (Yvelines) et son environmement. Bulletin d' information des geologues du Bassin de Paris 30(4): 3-16.

Lapparent de Broin, F. de., B. Lange-Badré, and M. Dutrieux. 1996. Nouvelles découvertes de tortues dans le Jurassique supérieurdu Lot (France) et examen du taxon Plesiochelyidae. Revue de Paléobiologie 15: 533-570.

Lee, M.S.Y. 1995. Historical burden in systematics and the interrelationships of 'parareptiles.' Biological Reviews 70: 459-547.

Lee, M.S.Y. 1997. Pareiasaur phylogeny and the origin of turtles. Zoological Journal of the Linnean Society 120: 197-280.

Maddison, W.P., and D.R. Maddison. 2000. MacClade: interactive analysis of phylogeny and character evolution. Version 4. Sunderland, MA: Sinauer Associates.

Maisey, J.G. 1990. Stratigraphy and depositional environment of the Crato member (Santana Formation), Lower Cretaceous of N.E. Brazil. In D.A. Grimaldi (editor), Insects from the Santana Formation, Lower Cretaceous, of Brazil, Bulletin of the American Museum of Natural History 195: 15-19.

Maisey, J.G. (editor). 1991. Santana fossils: an illustrated atlas, Neptune, NJ.: T.F.H. Publications.

Nixon, K.C. and J.M. Carpenter. 2000. On the other "Phylogenetic Systematics." Cladistics 16: 298-318.

Nixon, K.C., J.M. Carpenter, and D.W. Stevenson. 2003. The PhyloCode is fatally flawed, and the "Linnaean" system can easily be fixed. The Botanical Review 69: 111-120.

Page, R., A. Ardolino, and R.E. de Barrio, et al. 1999. Estratigrafia del Jurásico y Cretácico del Macizo de Somún Curá, Provincias de Río Negro y Chubut. In R. Caminos (editor). Geología Argentina: 460-488. Subsecretaría de Minería de la Nación; Buenos Aires.

Parham, J.F., and J.H. Hutchison. 2003. A new eucryptodire from the late Cretaceous of North America (Dinosaur Provincial Park, Alberta, Canada) Journal of Vertebrate Paleontology 23: 783-798.

Peng, J-H., and D.B. Brinkman, 1993. New material of Xinjiangchelys (Reptilia: Testudines) from the late Jurassic Qigu Formation (Shishugou Group) of the Pingfengshan locality, Junggar Basin, Xinjiang. Canadian Journal of Earth Sciences 30: 2013-2026.

Rauhut, O.W.M., G. Cladera, P. Vickers-Rich, and T.H. Rich. 2003. Dinosaur remains from the Lower Cretaceous of the Chubut Group. Argentina. Cretaceous Research 24: 487-497.

Rich, T.H., P. Vickers-Rich, F.E. Novas, R. Cuneo, P. Puerta, and R. Vacca, 1998. Theropods from the "middle" Cretaceous Chubut Group of the San Jorge sedimentary basin, central Patagonia: a preliminary note. Gaia 15: 111-115.

Rougier, G.W., M.S. de la Fuente, and A.B. Arcucci. 1995. Late Triassic turtles from South America. Science 268: 855-858.

Schuh, R.T. 2003. The Linnaean systen and its 250-year persistence. Botanical Review 69: $59-78$

Simpson, G.G. 1938. Crossochelys, Eocene horned turtle from Patagonia. Bulletin of the American Museum of Natural History 74: 221-254.

Smith, E. 1999. Black opal fossils of Lightning Ridge. East Roseville: Australia, Kangaroo Press. $112 \mathrm{pp}$. 
Sukhanov, V.B. 2000. Mesozoic turtles of Middle and Central Asia. In M.J. Benton, M.A. Shishkin, D.M. Unwin and E.N. Kurochkin (editors), The age of dinosaurs in Russia and Mongolia: 309-367. Cambridge: Cambridge University Press.

Sukhanov, V.B., and P. Narmandakh. 1974. [New Early Cretaceous turtle from continental deposits of the northern Gobi.] Mesozoic and Cenozoic faunas and biostratigraphy of Mongolia. The Joint Soviet-Mongolian Palaeontological Expedition. Trans. 1: 192-200. (in Russian).

\section{APPENDIX 1 \\ Character List}

1. NA, nasals
0 : present
1: absent

2. NA, size
0 : small, absent
1: very large

3. NA, nares divided
0 : yes
1: no

4. NA, nasomaxillary sinus
0 : absent
1: present

5. LA, lacrimal bone
0 : present
1: absent

6. LA, lacrimal foramen
0 : present
1: absent

7. PF, meet on midline
0 : no, separated by na-fr contact
1: yes

8. PF, pf-po contact

0 : present

1: absent (fr to orbit)

9. PF, pf-vo contact
0 : absent
1: present

10. PA, processus inferior parietalis

0 : small to absent
1: large

11. PA, pa-sq contact
0 : present
1: absent

Swofford, D.L. 2002. PAUP*. Phylogenetic analysis using parsimony (*and other methods). Version 4. Sunderland, MA: Sinauer Associates.

Tatarinov, L.P. 1959. A new turtle of the family Baenidae from the Lower Eocene of Mongolia. Paleontologicheskiy Zhurnal 1: 100-113 (in Russian).

Welles, S. 1962. A new species of elasmosaur from the Aptian of Columbia, and a review of the Cretaceous plesiosaurs. University of California Publications in Geological Sciences 46: 1-96.

12. PA, temporal emargination

$$
\begin{aligned}
& 0 \text { : fully roofed skull } \\
& \text { 1: shallow emargination }
\end{aligned}
$$$$
\text { 2: deep emargination }
$$

13. ST, supratemporal

$$
\begin{aligned}
& 0 \text { : present } \\
& \text { 1: absent }
\end{aligned}
$$

14. JU, cheek emargination

0 : absent, shallow, large ju

1: absent, shallow, large qj

2: moderate to deep

15. SQ, meet on midline

$$
\begin{aligned}
& 0: \text { no } \\
& 1: \text { yes }
\end{aligned}
$$

16. SQ, posterolateral process

$$
\begin{aligned}
& 0: \text { no } \\
& 1 \text { : yes }
\end{aligned}
$$

17. SQ, sq-so contact

$$
\begin{aligned}
& 0 \text { : absent } \\
& \text { 1: present }
\end{aligned}
$$

18. SQ, broad sq-qj contact

0 : absent, narrow

1: broad contact below cavum tympani

19. PO, length

0 : short

1: long

20. PO, po-sq contact

0 : present

1: absent

21. PM, premaxillary hook
0 : absent
1: present

22. MX, accessory ridge on triturating surface

0 : absent

1: present 
23. MX, length of facial region 0 : shorter, equal to orbit length 1: longer than orbit

24. VO, vomer
0 : double
1: single

25. VO, teeth
0 : present
1: absent

26. PAL, teeth

0 : present

1: absent

27. PAL, foramen palatinum posterius large

0 : small-moderate

1: very large

28. PT, vertical flange on proc pter ext

0 : absent
1 : present

29. PT, interpterygoid vacuity

0 : widely, slightly open

1: completely closed by medial extension of $\mathrm{pt}$

30. PT, canalis caroticus internus, posterior to foramen basisphenoidale

0 : absent

1: at least partially covered by bs-pt

2: covered by prootic

31. PT, canalis caroticus internus at least partially formed by $\mathrm{pt}$

0 : no

1: yes, distal to foramen basisphenoidale

32. PT, canalis caroticus lateralis vs canalis caroticus internus

0 : lateralis equal to, larger than internus

1: lateralis smaller than internus

33. PT, foramen posterius canalis carotici interni

0 : not formed by bs and $\mathrm{pt}$

1: formed by bs and pt, and located midway along bs

34. PT, middle ear with ossified floor formed by posteromedial pterygoid process
0 : process absent
1: present

35. PT, pt-bo contact

0 : absent

1: present

36. PT, deep concavity on qu ramus
0 : absent

1: present

37. PT, bs-pt space

0 : interpterygoid vacuity widely open

1: distinct space, perhaps a foramen posterius caroticum laterale, present

2: closed pt-bs suture, foramen basisphenoidale possibly present

38. PT, intrapterygoid slit

0 : absent, small

1: extensive, completely covering foramen basisphenoidale

39. QU, posterior pocket for stapes

0 : present

1: absent

40. QU, cavum tympani

0 : absent

1: present

41. QU, middle ear with complete lateral wall 0 : not complete

1: complete

42. QU, cavum tympani curved dorsally

0 : absent

1: present

43. QU, acute posterior margin

$0:$ no

1: yes

44. QU, incisura columellae auris

0 : separated from eustachian tube

1: with eustachian tube

45. QU, antrum postoticum

0 : absent

1: present

46. QU, covers op laterally

0 : no

1: yes

47. QU, cranioquadrate space

0 : relatively open

1: a well-defined canal

48. OP, processus paroccipitalis

0 : loosely articulated

1: tightly fused

49. OP, fenestra perilymphatica

0 : relatively large

1: relatively small

50. PR, anterior surface otic chamber

0 : faces more anterodorsally

1: faces more anteriorly, anteroventrally (processus trochlearis oticum)

51. PR, otic chamber thickness 
0 : anterior wall thin

1: anterior wall thick

52. SO, crista supraoccipitalis

0 : low to absent

1: distinct sagittal plate

53. SO, wide occipital plate

0 : wide occipital plate with depressions

1: absent

54. SO, supraoccipital with horizontal plate

0 : no

1: yes

55. EX, recessus scalae tympani

0 : not formed in bone

1: formed in bone with fenestra perilymphatica

56. BS, basipterygoid articulation

0 : open articulation

1: sutured joint

57. BS, foramen anterius canalis carotici interni

0 : widely separated

1: close together

58. BS, foramen basisphenoidale

0 : formed by bs, equals fpcci

1: formed by bs+pt, equals fpcci

2: formed by bs+pt, more posterior fpcci present

3: absent due to prootic forming fpcci

4: absent due to solid pterygoid covering

59. BS, foramen posterius canalis carotici interni

0 : equals foramen basisphenoidale

1: formed in part by bs

2: formed entirely by $\mathrm{pt}$

3: formed by prootic

60. BS, paired pits

0 : absent

1: present

61. BS, ventral bs/bo tubercle
0 : single
1: paired
2: absent

62. CA, columella auris

0 : thick, without distinct footplate

1: thin, with distinct wide footplate

63. JW, splenial

0 : present
1: absent

64. CE, proportions

0 : as high as wide

1: wider than high for posterior cervicals

65. CE, central articulations

0 : unformed

1: formed

66. CE, anterior end of 8th cervical

0 : unformed

1: cotyle

2: condyle

67. $\mathrm{CE}$, ribs

0 : present

1: absent

68. CE, transverse processes

0 : middle of centrum

1: anterior edge of centrum

69. CE, doubled transverse processes

0 : present on any cervical

1: absent on all

70. CE, 4th cervical articulation

0 : amphicoelous

1: biconvex

2: opisthocoelous

71. $\mathrm{CE}$, double articulation between 5 th and 6th

0 : absent

1: present

72. CE, double articulation between 6th and 7 th

0 : absent

1: present

73. CE, double articulation between 7 th and 8 th

0 : absent

1: present

74. $\mathrm{CE}$, strong ventral process

0 : absent on all centra

1: present on posterior centra

75. CE, neural spine on 8th cervical

0 : high

1: low

76. CE, 8th cervical centrum

0 : amphicoelous

1: procoelous

2: biconvex

77. CAU, tail rings

0 : absent

1: present 
78. CAU, tail club

0 : present

0 : absent

1: present

79. CAU, biconcave caudal near base of tail
0 : absent
1: present

80. CAU, central articulations

0 : posterior not procoelous

1: all centra procoelous

81. CAU, chevrons

0 : well developed and present on nearly all caudals

1: small or present on only a few caudals

82. $\mathrm{SH}$, coracoid foramen
0 : present
1: absent

83. $\mathrm{SH}$, coracoid columnar
0 : no, flat plate
1 : yes

84. POSTC, paddles formed by limbs
0 : absent
1: present

85. PEL, pelvis sutured to shell

0 : not sutured to shell

1: sutured to shell

86. PEL, pelvis narrow

0 : pelvis widely placed

1: ilia close to midline

87. CAR, first thoracic rib

0 : extends, nearly extends to peripherals

1: extends less than halfway across costal

88. CAR, anterior articulation of first thoracic centrum

0 : faces anteriorly to slightly anteroventrally

1: faces strongly anteroventrally

89. CAR, knob on ventral surface of nuchal that articulates with 8 th cervical
0 : absent
1: present

90. CAR, 10th thoracic rib

0 : reaches 8 th costal

1: free from costal

91. CAR, sacrum with dorsal 10

$0:$ no
$1:$ yes

92. CAR, 9th costal bone

93. CAR, suprapygal

0 : nearly equally subdivided into two

1: first suprapygal much smaller than second

2: only one suprapygal

3: second suprapygal absent or much smaller than first

4: second suprapygal divided by first

5: no suprapygal

6: three suprapygals

94. CAR, supramarginal scales

$0: 12$

1: 3

2: none

95. PLA, plastral fontanelles surrounded by hyo-hypoplastra

0 : absent

1: retained in adult

96. PLA, carapace-plastron attachment

0 : sutured

1: ligamentous

97. PLA, plastral buttresses

0 : reaching peripherals

1: reaching costals

98. PLA, entoplastron separating epiplastra

0 : yes

1: no

99. PLA, dorsal process on epiplastron

0 : large, reaches carapace

1: smaller than length of epiplastron

2: absent

100. PLA, epiplastron

0 : broad

1: narrow

101. PLA, epiplastral beak

0 : absent

1: present

102. PLA, bridge of plastron

0 : broad

1: narrow

103. PLA, mesoplastra

0 : present

1: absent

104. PLA, xiphiplastron

0 : moderately broad

1: narrow 
105. PLA, xiphiplastron median notch

0 : absent

1: present

106. PLA, gular scales

0: 2 pairs

1: 1 pair

107. PLA, inframarginals

0: 3-4 pairs

1: $0-2$ pairs (axillary, inguinal)

108. PLA, abdominal scute relative to midline

0 : meets on midline

1: withdrawn from midline

109. PLA, pectoral scute

0 : not on epiplastron

1: on epiplastron

110. PLA, femoral-anal sulcus

0 : not reaching hypoplastron

1: reaching hypoplastron

111. PLA, midline sulcus sinuous

0 : no

1: yes

\section{APPENDIX 2 \\ DATA MATRIX}

"Synapsida/Diapsida"

00000000000000000000??00000?0000000000000000000000000000000000000000000000000000000000 ?-

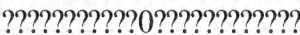

\section{Proganochelys}

$0000000000000000000000000000000 ? 00000000000$ 0000000000000100000000000000000000100000000 $000000 ? 000000000000000000$

Australochelys

?000?0??0??0?00000??000???0?000?0000001110000111 ??010001?0001??0??????????????????????????????????????????

\section{Palaeochersis}

0000?0??0??0?00000??001???0?000?0000001111100111?0010001?00010?00?0?????????0000000000???????0000000000000?0??0

\section{Proterochersis}

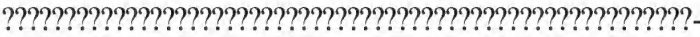

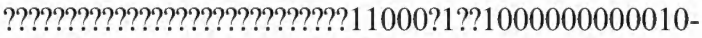
$00 ? 00$
Megapleurodira

0010110101(01)11200000(01)(01)(01)0111001201000(01)2011111(01)111100011011(01)3302100(01)(12) 101(012)00000(012)0000111011(01)0001121(01)0(01) $12000(01) 01010 ? 00$

Kayentachelys

$0010110111001000001000011 ? 01000 ? 00001011111-$ 0111101111011000021?00000000000?000000110000000001200001000000000?00

\section{Kallokibotion}

000?110?11001000001000011101100001101011111$11111 ? 1111011 ? 0002 ? ? 00000000000000 ? 000 ? ? 0000-$ $000 ? 13200112000000000 ? 00$

Mongolochelys

0010110011001010101001011101100001001011111 $0111101111011 ? 0002 ? ? 000000000000 ? 000001 ? 00 ? 0-$ $01 ? 200210011000000000 ? 00$

Pleurosternidae

00101101110(01)10000010100111011000111020111$11011111111101101002 ? 000000000000 ? 000000110$ 00000?01(01)2001110000000000(01)0

Baenidae

00101101110(01)12000010000111011001111020111$11111111111101101002100(01) 00010000000000001-$ 1000000?01(14)200112000000000010

Xinjiangchelys

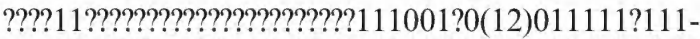
$1 ? 11110 ? 102112 ? ? 0000100000000 ? ? 10 ? ? ? 00 ? 100 ? 01 ?-$ $2 ? 10110011000000(01) 1$

\section{Solnhofia}

$0010111111111 ? 00001 ? 00111101111001102011111$ 01111011110111220210000100000000?00?00?1000?????162110????0100?????

Plesiochelyidae

001011111101?200001000011101111001(01)0201111101111011110110420210000100000000000000110 00000?0102(01)0112000100000?00

\section{Meiolania}

01(01)1110011001101110001011101111?011011111$11111110111111102202 ? 0011000100000111000110$ 00001101?2110110001000?00?0

Ninjemys 
??0111?????01?0111??01011101111?01?0111111111111?11111?1???????????????????11??????????????????????????????

\section{Niolamia}

$011 ? 1100 ? ? 001 ? 0111 ? ? 000111 ? 1111001 ? 0101111111-$ 11101111111?2102???????????????1????????????????????????????????

\section{Chubutemys}

?01?11?0??0010000??00001110?111101?01011111?1111???11011?21021?012?1????0??2???????????0?????2??????????????

\section{Sinemys}

0010110111121200000100011111111001001011111 0111101111011021?2???1201020?0012??110??00?00$0 ? 01 ? 2110121001001 ? 00 ? 0$

\section{Otwayemys}

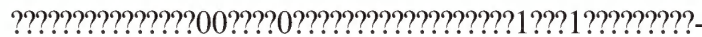

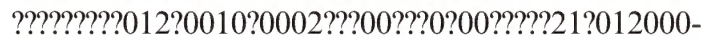
$100 ? ? 0 ? 00$

\section{Hangaiemys}

0010111111021200001010011111111001111011111 ?1111?111101102212??01?11?100010???????????1????10201012101100100000

\section{Dracochelys}

?01?11?1?1121?00001?1001111?11100111101111101111?1111011?22?2??012000?0??112????????0?000?0$10 ? ? 1012 ? ? 110 ? 1 ? 0 ? ? 0$
Ordosemys

0010110?11111200001000011101111001111011111011110111101112112???1201010?0012??110??00?00$1 ? ? ? 02110121 ? 1100 ? ? 0000$

\section{Judithemys}

0010111?1102120000100001110111100110101111101111?111101102212??0111111??01010011011000100??102010121011101?0000

Chelydridae

1010111011121000001010(01)1110111110110201111101111011110110420211111111111011100110110 00110(01)01(01)211012(01)(01)11101(01)1110

Chelonioidea

001011(01)(01)1(01)(01)(12)100000100(01)0111011110011(01)(12)011111011110(01)111011142(01)211111111100(01)1010001111100(01)(01)1001(023)21101210(01)1101(01)0010

Trionychoidea

1010111(01)111(12)120000110(01)01110111100110(12)011111011110(01)1110110(24)20211112111201$11110001111000110101(25) 2(01) 0(01) 120001000(0-$ 1)000(01)

Testudinoidea

1010111(01)111(12)120000010(01)011101111101(01)0(12)01111101111011110110(24)2021111211111111120001111000110001(13)2(01)01120001001(01)0000 
Complete lists of all issues of the Novitates and the Bulletin are available at World Wide Web site http://library.amnh.org/pubs. Inquire about ordering printed copies via e-mail from scipubs@amnh.org or via standard mail from: American Museum of Natural History, Library-Scientific Publications, Central Park West at 79th St., New York, NY 10024. TEL: (212) 769-5545. FAX: (212) 769-5009.

(2) This paper meets the requirements of ANSI/NISO Z39.48-1992 (Permanence of Paper). 